LBNL-56397

\title{
AN EVALUATION OF TECHNOLOGIES FOR REAL-TIME MEASUREMENT OF RATES OF OUTDOOR AIRFLOW INTO HVAC SYSTEMS
}

\author{
William J. Fisk, David Faulkner, Douglas P. Sullivan \\ Indoor Environment Department \\ Environmental Energy Technologies Division \\ Lawrence Berkeley National Laboratory \\ Berkeley, CA 94720
}

September 27, 2004

This work was supported by the assistant Secretary for Energy Efficiency and Renewable

Energy, Building Technologies Program of the U.S. Department of Energy under contract DEAC03-76SF00098. 


\begin{abstract}
During the last few years, new technologies have been introduced for real-time continuous measurement of the flow rates of outdoor air (OA) into HVAC systems; however, an evaluation of these measurement technologies has not previously been published. This document describes a test system and protocols developed for a controlled evaluation of these measurement technologies. The results of tests of four commercially available measurement technologies and one prototype based on a new design are also summarized. The test system and protocol were judged practical and very useful. The series of tests identified three commercially available measurement technologies that should provide reasonably accurate measurements of $\mathrm{OA}$ flow rates as long as air velocities are maintained high enough to produce accurately measurable pressure signals. In HVAC systems with economizer controls, to maintain the required air velocities the OA intake will need to be divided into two sections in parallel, each with a separate OA damper. The errors in OA flow rates measured with the fourth commercially available measurement technology were $20 \%$ to $30 \%$ with horizontal probes but much larger with vertical probes. The new prototype measurement technology was the only one that appears suitable for measuring OA flow rates over their full range from $20 \%$ OA to $100 \%$ OA without using two separate OA dampers. All of the measurement devices had pressure drops that are likely to be judged acceptable. The influence of wind on the accuracy of these measurement technologies still needs to be evaluated.
\end{abstract}

\title{
Background
}

Ventilation, i.e., providing outdoor air (OA), has a substantial influence on building energy consumption, occupant health, and occupant satisfaction with the indoor environment. The quantity of energy used for ventilation in the U.S. service sector (i.e., commercial, institutional, and government buildings) is uncertain, but clearly substantial. Emmerich and Persily (1998) predicted that $10.9 \mathrm{kBTU} / \mathrm{ft}^{2}\left(124 \mathrm{MJ} / \mathrm{m}^{2}\right)$ of heating and cooling energy would be used for ventilating U.S. office buildings, if all offices had a ventilation rate of $20 \mathrm{cfm}\left(10 \mathrm{~L} \mathrm{~s}^{-1}\right)$ per person. However, existing data from office buildings indicate that the average minimum ventilation rate is well above of $20 \mathrm{cfm}\left(10 \mathrm{~L} \mathrm{~s}^{-1}\right)$ per person. The most representative data for estimating ventilation rates (Womble et al. 1996) is from U.S. Environmental Protection Agency (EPA) survey of a representative sample of 100 office buildings. The survey included 40 measurements taken when ventilation rates should be at the minimum because outdoor air temperatures were greater than $75^{\circ} \mathrm{F}\left(24^{\circ} \mathrm{C}\right)$. If we use the carbon dioxide data collected from these 40 buildings, the estimated ${ }^{1}$ average minimum rate of outdoor air supply during this survey was 28 cfm/occupant (14 L/s), or 140\% of the value assumed in the analysis by Emmerich and Persily (1998). Because energy used for ventilation increases almost linearly with the minimum ventilation rate, the estimated energy consumption for ventilation is then $15.3 \mathrm{kBTU} / \mathrm{ft}^{2}\left(170 \mathrm{MJ} / \mathrm{m}^{2}\right)$. If we assume that, on average, all service sector buildings in the US use this amount of energy per unit floor area for ventilation, the total energy consumed is roughly 1 Quad $(1 \mathrm{EJ})$. We expect that the actual energy use for ventilation could be considerably higher because many types of service sector buildings have a higher occupant density or are ventilated for longer periods of each day than offices. If the average minimum rate of OA supply was reduced ${ }^{2}$ to bring rates in alignment with the current standards, the energy savings would be approximately 0.3 Quad (0.3 EJ).

\footnotetext{
${ }^{1}$ For this estimate, we assumed that on average indoor $\mathrm{CO}_{2}$ concentrations only reached $80 \%$ of the true equilibrium value and that the $\mathrm{CO}_{2}$ generation rate per person was $0.011 \mathrm{cfm}(0.0052 \mathrm{~L} / \mathrm{s})$.

${ }^{2}$ Based on the available data from the Base Study, to bring the average rate in accordance with standards, rates of outdoor air supply would be reduced in two thirds of buildings and increased in one third of buildings.
} 
The "correct" minimum rate of outdoor air supply to maintain occupant health and satisfaction with air quality is not well known. The minimum recommended rate for offices in the ASHRAE ventilation standard (ASHRAE 1999) was, until recently, $20 \mathrm{cfm}(10 \mathrm{~L} / \mathrm{s})$ per occupant. The current ventilation standard (ASHRAE 2001) has a minimum ventilation requirement per person and per unit floor area that, with typical occupant density assumptions, translates into approximately the same per person requirement as the older standard. The scientific literature on the relationship of ventilation rates with health and occupant satisfaction was reviewed by Seppanen et al. (1999). On average, lower ventilation rates were associated with increased prevalences of communicable respiratory illnesses (e.g., common colds), increased prevalence rates of sick building syndrome (SBS) symptoms, and diminished satisfaction with indoor air quality. The evidence of adverse effects was strongest when ventilation rates were reduced below $20 \mathrm{cfm}\left(10 \mathrm{~L} \mathrm{~s}^{-1}\right)$ per person; however, several studies reported benefits of increasing ventilation rates above $20 \mathrm{cfm}\left(10 \mathrm{~L} \mathrm{~s}^{-1}\right)$ per person. Clearly, there is a need to strike a balance between the potential benefits to health of increased ventilation and the beneficial energy savings from reduced ventilation.

Despite the substantial influences of ventilation rates on energy use and health, very few U.S. buildings have an integral system for measuring ventilation rates. The typical practice ${ }^{3}$ in office and institutional buildings, which are the primary focus of this report, is to have an air balance company measure the OA flow during a period of building commissioning or airflow balancing and adjust the positions of the dampers for OA, recirculation air, and exhaust air to obtain the desired minimum rate of OA supply. However, accurately measuring OA airflow into HVAC systems is technically very challenging, even for researchers with special instrumentation, and typical practices often do not satisfactorily determine minimum ventilation rates. For example, the minimum OA flow is sometimes based on the difference between supply and return air flow rates, with each of these flow rates determined using an air flow measuring station in the airstream ${ }^{4}$. Modest errors in measurements of supply and return air flow rates can produce a large error in the difference between these two flow rates (Kettler 1995). An alternative method for measuring OA flows is a velocity traverse with a rotating vane anemometer at the exterior face of the outdoor air inlet. However, the non-stable (due to winds) and spatially non-uniform air velocities at the outdoor air intakes, plus the difficulty in determining the effective area of the intake can result in large errors (Howell et al. 1987, Krarti et al. 1999). Another alternative measurement approach is to determine the outdoor airflow from the product of a measured supply airflow rate and the percentage of outdoor air $(\% \mathrm{OA})$ in the supply air stream, which is determined from air temperature measurements and an energy balance calculation. However, non-uniform airstream temperatures and small differences between temperatures can cause large errors in the estimated \%OA and associated OA flow rate (Krarti et al. 1999).

Even if air balance professionals could provide perfect measurements of OA flow rates during their occasional visits to buildings, the OA flow is not always stable. The actual rates of OA flow will often vary with changes in wind and as the supply air flow rates of variable air volume (VAV) HVAC systems are modulated. In addition, minimum damper positions, which affect OA flow rates may change from those set by the air balance professional due to deliberate adjustments by building operators and to wear or failures in the damper actuators and linkage.

\footnotetext{
${ }^{3}$ In some larger buildings, a separate OA injection fan is used to provide minimum OA. The injection fan could have an accompanying system for measuring OA flow rates.

${ }^{4}$ In some buildings, the OA flow scheme is based on a method called "return fan tracking". As the flow through the supply fan changes, the system adjusts the return fan speed in an attempt to maintain a fixed difference in flow rate. As discussed by Schroeder, in practice return fan tracking often maintains the OA flow needed to maintain the building pressurized, which does not necessarily equal the recommended minimum OA supply rate. (Schroeder et al. 2000). This method also fails if the exhaust flow rate is non-zero during minimum OA supply
} 
Given these measurement challenges it is not surprising that the ventilation rates measured in surveys by researchers using tracer gas based measurement systems or other methods (e.g., Turk et al. 1987, Lagus Applied Technologies 1995, Persily 1989, Persily and Gorfain 2004) vary widely and often differ substantially from the minimum ventilation rates specified in the applicable codes and in design documents. Because the limited available data indicate that most buildings have minimum ventilation rates substantially exceeding code requirements, routine use of OA measurement systems may be one of the most cost-effective methods of reducing energy use in these over ventilated buildings. A significant but smaller fraction of buildings provide less ventilation than specified in codes, and OA measurement systems could reduce IAQ problems associated with insufficient ventilation.

There are significant obstacles to cost-effective and accurate measurements of OA flow rates. First, measurements are challenging because OA intake velocities are intentionally kept low in order to minimize rain and snow from being drawn into the air handler. Sizing of the OA air inlet for the entire OA flow into the air handler during economizer operation compounds the problem. The result is particularly low OA intake velocities during periods of minimum OA supply (e.g., 20\% of maximum OA supply), when measurements are most important. Based on a review of specifications of louvers, the maximum recommended air velocity within the "free area" of an intake louver is usually 700 to 2500 fpm (3.5 to $13 \mathrm{~m} \mathrm{~s}^{-1}$ ) to minimize entrainment of rain and snow. These velocities occur with the maximum flow at the OA intake during economizer operation with $100 \%$ outdoor air. Since the minimum OA supply may be only $20 \%$ of the full supply air flow rate, the velocities of OA in the free area of the louver during periods of minimum OA flow will be only 140 to $500 \mathrm{fpm}\left(0.5\right.$ to $\left.2 \mathrm{~m} \mathrm{~s}^{-1}\right)$. Because the cross sectional area for flow inside the louver is less than the nominal face area of the louver, the velocities upstream of the outside air louver may be $30 \%$ to $50 \%$ of the velocities in the free area of the louver. At these low velocities the dynamic pressure of the moving air, which is often used in to measure air speed, is only thousandths of an inch of water (a fraction of a Pascal), which is too low for accurate measurements in field settings.

The geometry of the OA intake and its impact on velocity profiles further complicates the measurements. The outdoor air passes through a bird screen, a set of louvers, and an adjustable OA damper. Downstream of the louvers or OA dampers the speed and direction of airflow will normally vary markedly across the flow cross section; thus, averaging of velocity measurements made at a few locations in the cross section may also lead to large measurement errors. At the exterior face of the OA intake, measurements are problematic because even normal winds cause a large fluctuation in air velocity. While these problems and the need for better measurement and control of OA ventilation rates have been recognized for many years, until recently there has been little progress toward meeting this need. The review of Krarti et al. (1999) on measurement and control of OA flow in variable air volume systems includes a summary of much of the recent research. In particular, Krarti et al. (1999) point out that the long unobstructed OA ducts needed for most flow rate measurements will generally be impractical, and they identify the following as promising alternatives:

1. providing a separate outdoor air duct for the minimum outdoor airflow with air velocities maintained sufficiently high for use of Pitot-static tube arrays;

2. maintaining a constant pressure drop across the OA louvers and dampers during minimum outdoor air conditions; and

3. using a $\mathrm{CO}_{2}$ mass balance to compute the percentage of outdoor airflow (\%OA) and multiplying by the separately metered supply airflow to determine the outdoor airflow.

\footnotetext{
${ }^{5}$ Minimum total cross sectional area for airflow through a louver.
} 
While each of these alternatives has merit, they also have some drawbacks. Alternative 1 (providing a separate OA duct) will often be unattractive to designers because of space constraints and costs, especially for small to moderate size HVAC systems. Alternative 2 is a flow control strategy but requires a separate measurement system for calibration of flow versus pressure drop in field settings. As indicated above, accurate field-based calibrations will be difficult. Alternative 3 requires an accurate measurement system for supply flow rates ${ }^{6}$ and is not applicable unless indoor $\mathrm{CO}_{2}$ concentrations are substantially above outdoor concentrations. Persily and Gorfain (2004) estimated that errors in alternative 3 exceeded $80 \%$ in almost $90 \%$ of 320 measurements. Also, alternatives 1 and 2 only provide a measurement during periods of minimum outdoor air supply, although OA supply rates should be higher during economizer operation.

Within the past few years, manufacturers have pursued another option -- the direct real-time measurement of airflow through the OA intake using a sensor system located at the OA intake. A handful of related measurement technologies have emerged on the market within the last few years. The objectives of the research discussed in this paper was to evaluate the performance (measurement accuracy and pressure drop) of these emerging direct measurement technologies. We also present results of the evaluation of a new measurement concept based on our own design. A separate paper being prepared will review the causes of measurement errors and describe some approaches for overcoming these sources of error.

\section{Approach}

Test system description

The laboratory test system constructed for this research and illustrated diagrammatically in Figure 1, has a changeable OA intake louver and damper system, air recirculation ductwork, a variable speed fan, recirculation and exhaust dampers, and a precision "reference" airflow meter upstream of the location of air exhaust. The reference airflow meter has a built-in airflow straightener and, a nozzle, and a Pitotstatic tube like velocity sensor, and a manufaturer's rated accuracy of $\pm 0.5 \%$. Based on our evaluations of this type of flow meter using the Pitot tube traverse method, errors in measuring the flow meter's pressure signal are the largest source of flow rate measurement error. Two different sizes of reference flow meters are used for accurate measurements over a wide range of airflow. Accounting for the drift in the calibration of our pressure transducer, for reference flow rates exceeding $250 \mathrm{cfm}\left(118 \mathrm{~L} \mathrm{~s}^{-1}\right)$, we estimate that the accuracy of the reference flow rate measurements is approximately $\pm 7 \%$ or better. The recirculation flow rates are measured with less accuracy (estimated $\pm 20 \%$ ) based on the pressure drop across an iris-style damper, relying on the manufacturer's calibration of flow versus pressure drop. Highly accurate measurements of recirculation air flow rates is not important for our tests.

In the test system, technologies for measuring OA flow can be installed per manufacturers specifications. Turning vanes are installed in the bend of the recirculation ductwork upstream of the location where recirculated and outdoor air mix. Independent control of the OA and recirculation air flow rates can be accomplished by adjusting the position of the three dampers ${ }^{7}$.

Because the system is sealed to reduce air leakage to a negligible level ${ }^{8}$, the flow of OA into the test system effectively equals the exhaust airflow rate, which is measured with the reference airflow meter.

\footnotetext{
${ }^{6}$ Use of a the same $\mathrm{CO}_{2}$ sensor to measure the concentrations in outdoor, return, and supply air is recommended to reduce errors.

${ }^{7}$ Flow rates were not stable if the fan speed was reduced below full speed, thus, we used only the dampers to modulate flow rates.

${ }^{8}$ All joints were carefully caulked and smoke tubes were used to check for leaks and the system was pressure tested at the maximum operating pressure to assure negligible leakage.
} 
Thus, the accuracy of the OA measurement technology being tested is determined by comparison to the reference airflow meter, and the percentage measurement error (\%error) is calculated from the following equation:

$$
\% \text { error }=100 \%\left(Q_{m t}-Q_{r e f}\right) / Q_{r e f}
$$

where $Q_{m t}$ and $Q_{r e f}$ are the OA flow rates from the measurement technology being evaluated and the reference flow meter, respectively.

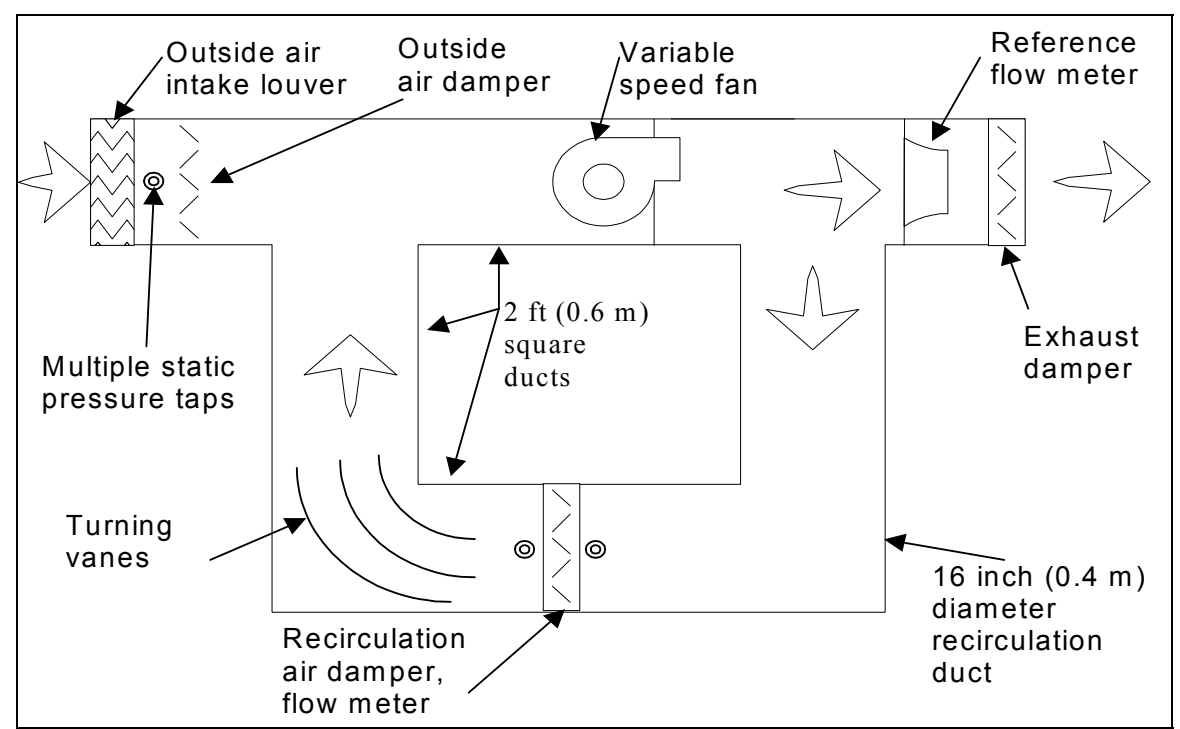

Figure 1. Illustrative diagram of test system

Static pressure taps are installed at a number of locations to enable measurements of pressure drops across the measurement systems. Per specifications in ANSI/ASHRAE standards (ASHRAE 1999a, ASHRAE $1999 \mathrm{~b})$, the taps are $0.07 \mathrm{inch}(1.8 \mathrm{~mm})$ diameter holes in the duct wall with a smooth inner face.

The output signals of pressure transducers are logged with a data acquisition system. Instrumentation specifications and our estimates of accuracy during the tests are provided in Table 1. The calibration of the eight-channel pressure transducer system was checked using a micro-manometer that has a micrometer and electrical circuit for precisely measuring the height of the fluid column. A skilled user of the micro-manometer can obtain measurements repeatable within 0.0005 inch water $(0.1 \mathrm{~Pa})$. However, after accounting for instrument drift, the errors in pressure measurements may be as high as $\pm 2 \mathrm{~Pa}$.

The velocity profile of air entering an OA intake may be affected by winds. Our limited tests (described in Fisk et al. 2003) have indicated that winds can affect the accuracy of OA measurement technologies. In theory, the placement of OA intakes near rooftops, walls of buildings, or walls used as visual (sometimes called architectural) screens, may affect the entering velocity profiles and the accuracy of OA flow measurement technologies, although in our tests to date these nearby surfaces have not affected measurement accuracy. Fisk et al. (2003) describes laboratory-based methods for preliminary investigations of the influence of winds and surfaces on the accuracy of the measurement technologies; however, the remainder of this paper focuses on conditions without winds and without surfaces located within $3 \mathrm{ft}(1 \mathrm{~m})$ of the OA intake 
Table 1. Instrumentation used with the test system

\begin{tabular}{|c|c|c|c|}
\hline $\begin{array}{l}\text { Parameter } \\
\text { Measured }\end{array}$ & Type of Instrument & Measurement range & $\begin{array}{l}\text { Manufacturer's } \\
\text { Rated Accuracy } \\
\text { [estimated accuracy } \\
\text { in use] }\end{array}$ \\
\hline $\begin{array}{l}\text { Exhaust } \\
\text { (reference) } \\
\text { flow rate }\end{array}$ & $\begin{array}{l}18 "(46 \mathrm{~cm}) \text { and } 10 "(25 \\
\mathrm{cm}) \text { flow meters flow } \\
\text { meters have a flow } \\
\text { straightener and converging } \\
\text { nozzle, with Pitot-static type } \\
\text { sensor centered at outlet of } \\
\text { nozzle }\end{array}$ & $\begin{array}{l}\text { Large } 18 "(46 \mathrm{~cm}) \text { flow meter: } 690 \\
\text { to } 3700 \mathrm{cfm}\left(0.33 \text { to } 1.75 \mathrm{~m}^{3} \mathrm{~s}^{-1}\right) \\
\text { with pressure signal of } 0.4 \text { to } 1.2 \\
\text { inch water }(10 \text { to } 290 \mathrm{~Pa}) \\
\text { Small } 10 "(25 \mathrm{~cm}) \text { flow meter: } 330 \\
\text { to } 1160 \mathrm{cfm}\left(0.16 \text { to } 0.55 \mathrm{~m}^{3} \mathrm{~s}^{-1}\right) \\
\text { with pressure signal of } 0.1 \text { to } 1.3 \\
\text { inch water }(26 \text { to } 330 \mathrm{~Pa})\end{array}$ & $\begin{array}{l}0.5 \% \text { of reading } \\
{[ \pm 7 \% \text { or better for }} \\
\text { reference flow } \\
\text { exceeding } 250 \mathrm{cfm} \\
\left.\left(0.09 \mathrm{~m}^{3} \mathrm{~s}^{-1}\right)\right]\end{array}$ \\
\hline $\begin{array}{l}\text { Recirculation } \\
\text { flow rate }\end{array}$ & $\begin{array}{l}16 "(41 \mathrm{~cm}) \text { Iris Damper } \\
\text { with integral differential } \\
\text { pressure flow meter }\end{array}$ & $\begin{array}{l}150 \text { to } 4000 \mathrm{cfm}\left(0.07 \text { to } 1.9 \mathrm{~m}^{3} \mathrm{~s}^{-}\right. \\
\left.{ }^{1}\right) \text { for differential pressure range of } \\
0.1 \text { to } 2.0 \text { inch water }(25 \text { to } 500 \mathrm{~Pa})\end{array}$ & $\begin{array}{l} \pm 7 \% \text { of reading } \\
{[ \pm 20 \%]}\end{array}$ \\
\hline $\begin{array}{l}\text { Pressure } \\
\text { difference }\end{array}$ & $\begin{array}{l}\text { Eight channel electronic } \\
\text { differential pressure } \\
\text { transducer }\end{array}$ & \pm 1.6 inch water $( \pm 400 \mathrm{~Pa})$ & $\begin{array}{l}\text { Larger of } \pm 0.001 \text { inch } \\
\text { water }( \pm 0.2 \mathrm{~Pa}) \text { or } \pm \\
1 \% \text { of reading } \\
{[ \pm 2 \mathrm{~Pa} \text { or better }]}\end{array}$ \\
\hline
\end{tabular}

\section{Test protocol}

The protocol for evaluating measurement technologies was straightforward. By adjusting dampers, OA flow rates were varied over the desired range. Recirculation air flow rates were adjusted so that the percentage of outdoor air (\%OA), [i.e., outdoor air flow rate divided by outdoor plus recirculation flow rate, expressed as a percentage] ranged from approximately $10 \%$ to $100 \%$.

In tests of the first two measurement systems, we set the OA damper at $1 / 4,1 / 2,3 / 4$, and fully open positions and used the exhaust and recirculation damper to obtain the desired flow rates. After completing tests of the second measurement technology it was apparent that the air recirculation process could, under some circumstances, disturb the velocity or pressure profiles upstream of the OA damper and increase errors in measurements of OA flow rate. Therefore, in our analyses of the data from MT2, we have omitted results $^{9}$ from tests with a pressure drop across the OA damper smaller than 0.02 IWG $(5 \mathrm{~Pa})$. In addition, in the tests of the third through fifth measurement technologies we either a) varied the rate of OA flow by adjusting the OA air damper and maintaining the exhaust damper fully open; or b) varied the rate of OA flow by adjusting the exhaust air damper opening while maintaining the OA damper sufficiently closed so that the pressure drop across this damper was approximately 0.04 IWG (10 Pa). Maintaining this pressure drop across the OA damper largely eliminated the measurement errors associated with recirculation downstream of the OA damper.

\section{Louvers used during tests}

Experiments took place using three different types of louvers and the OA inlet that span over a wide range of louver designs. Figure 2 illustrates a cross section of a part of each louver.

Table 2 summarized characteristics of the louvers including the maximum recommended air velocities and the corresponding air flow rates for the nominal $2 \mathrm{ft}$ by $2 \mathrm{ft}(0.6 \mathrm{~m}$ by $0.6 \mathrm{~m})$ louvers used in the tests. The table also provides the air velocities and flow rates at $20 \%$ of the maximum recommendations. These

\footnotetext{
${ }^{9}$ Overall findings were essentially unchanged due to omission of these data.
} 
numbers indicate the minimum velocities and flow rates expected in an HVAC system with an economizer that has a minimum OA flow rate equally to $20 \%$ of the maximum OA flow rate

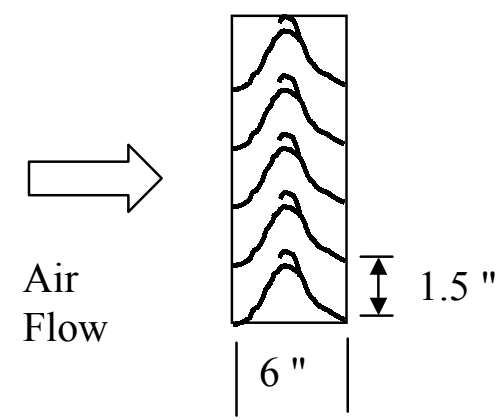

Louver 1

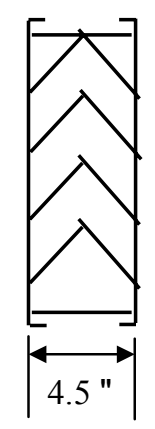

Louver 2

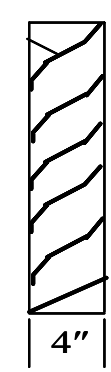

Louver 3

Figure 2. Cross sections of louvers used during tests with Louver 1 viewed from the top and Louvers 2 and 3 are viewed from the side.

Table 2. Characteristics of the louvers

\begin{tabular}{|c|c|c|c|}
\hline Parameter & Louver 1 & Louver 2 & Louver 3 \\
\hline \multicolumn{4}{|c|}{ Free area of louver ${ }^{10}$} \\
\hline $\mathrm{ft} 2$ & 1.24 & 1.23 & 1.75 \\
\hline $\mathrm{m} 2$ & 0.115 & 0.114 & 0.163 \\
\hline \multicolumn{4}{|c|}{ Max recommended free area velocity } \\
\hline fpm & 1856 & 500 & 696 \\
\hline $\mathrm{m} / \mathrm{s}$ & 9.43 & 2.54 & 3.54 \\
\hline \multicolumn{4}{|c|}{ Flow rate at maximim free area velocity } \\
\hline $\mathrm{cfm}$ & 2301 & 615 & 1218 \\
\hline $\mathrm{L} / \mathrm{s}$ & 1086 & 290 & 575 \\
\hline \multicolumn{4}{|c|}{$\begin{array}{l}\text { Maximum velocity upstream and downstream of } \\
\text { louver }\end{array}$} \\
\hline fpm & 575 & 154 & 305 \\
\hline $\mathrm{m} / \mathrm{s}$ & 2.92 & 0.78 & 1.55 \\
\hline \multicolumn{4}{|c|}{ Flow rate at $20 \%$ of maximum recommended } \\
\hline $\mathrm{cfm}$ & 460 & 123 & 244 \\
\hline $\mathrm{L} / \mathrm{s}$ & 217 & 58 & 115 \\
\hline \multicolumn{4}{|c|}{$\begin{array}{l}\text { Velocity upstream and downstream of louver at } \\
20 \% \text { of maximum recommended }\end{array}$} \\
\hline fpm & 115 & 31 & 61 \\
\hline $\mathrm{m} / \mathrm{s}$ & 0.58 & 0.16 & 0.31 \\
\hline
\end{tabular}

\section{$\underline{\text { Measurement technologies }}$}

This report summarizes results of our evaluations of five OA measurement technologies under conditions without winds at the OA intake. Measurement technology 3 (MT3) was tested using all three louvers. In all cases, the overall cross sectional dimensions of the OA inlet section was $2 \mathrm{ft}$ by $2 \mathrm{ft}(0.6 \mathrm{~m}$ by $0.6 \mathrm{~m})$.

${ }^{10}$ The velocity at which the results of a moisture entrainment test meet certain criteria 
Measurement technology number 1 (MT1), illustrated in Figure 3, integrates a set of closely spaced (1.5 inch [3.8 cm]) vertical louvers, identical to those identified as Louver 1, with a set of downstream airflow sensing blades that extend over the height of the louver system and that are centered between adjacent blades of the louver. The manufacturer provides a calibration curve in terms of average air velocity through the free-area of the louver system versus pressure signal from the airflow sensing blades. The airflow sensing blades appear to be designed to provide a pressure signal proportional to the average velocity along a vertical path centered between adjacent louvers. Compared to many louver systems, the MT1 louver system also has a relatively high recommended maximum free area velocity which helps to maintain a measurable pressure signal. The shape of the airflow-sensing blade should also yield a larger pressure signal than a standard Pitot-static tube.

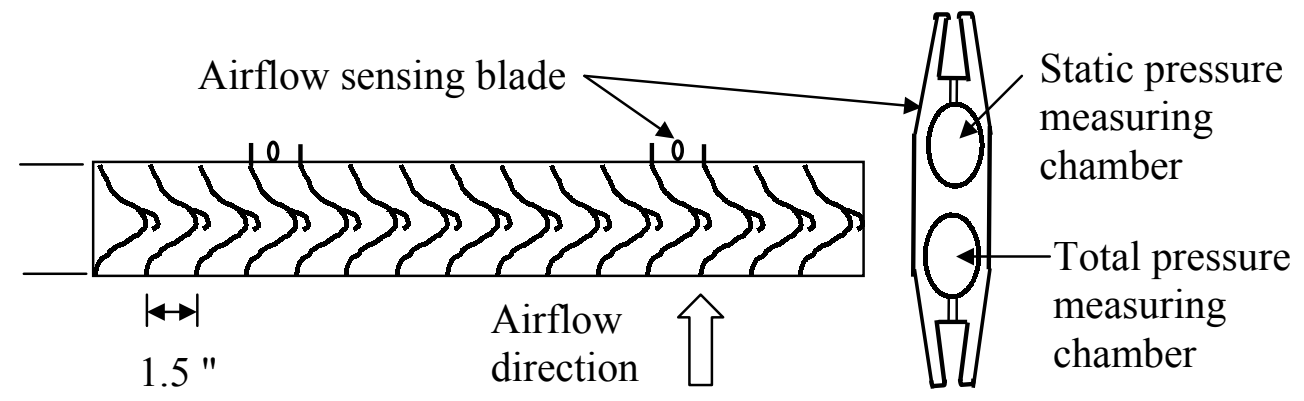

Figure 3. Illustration of outdoor airflow measurement technology number 1 (MT1). Top views of cross section of the louvers and airflow sensing blades are shown. The airflow sensing blades extend vertically nearly the full height of the louver system.

The tests of MT1 were conducted with a nominal $2 \mathrm{ft}$ by $2 \mathrm{ft}(0.6 \mathrm{~m}$ by $0.6 \mathrm{~m})$ louver system with two downstream sensing blades. The manufacturer's minimum "velocity requirement" for MT1 was $345 \mathrm{fpm}$ $\left(1.8 \mathrm{~m} \mathrm{~s}^{-1}\right)$ in the free area of the louver. The corresponding OA flow is $430 \mathrm{cfm}\left(0.20 \mathrm{~m}^{3} \mathrm{~s}^{-1}\right)$.

Manufacturer's data indicate that the pressure drop across the louver system (without a bird screen) ranges nonlinearly from 0.01 inch water $(2.5 \mathrm{~Pa})$ with an air velocity through the free area of $470 \mathrm{fpm}(2.4$ $\left.\mathrm{m} \mathrm{s}^{-1}\right)$ to 3 inch water $(747 \mathrm{~Pa})$ with a velocity of $7300 \mathrm{fpm}\left(37 \mathrm{~m} \mathrm{~s}^{-1}\right)$. MT1 was installed with 27.5 inch $(70 \mathrm{~cm})$ of straight duct located between the downstream edge of the louver and the upstream edge of the fully open OA damper

Measurement Technology number 2 (MT2), illustrated in Figure 4, uses thermal dispersion anemometry sensors installed at the periphery of multiple holes in one or more tubes (called probes) that are inserted perpendicular to the flowing air. A self-heated thermistor and unheated thermistor are located $180^{\circ}$ apart at the periphery of each hole, and the airflow through the hole affects the extent to which the unheated thermistor records a temperature above ambient, leading to a velocity signal. Associated electronics power the sensors and average the signal from multiple sensors, yielding an average velocity. Based on manufacturers specifications, the sensors are temperature compensated between $-20{ }^{\circ} \mathrm{F}$ and $160{ }^{\circ} \mathrm{F}\left(-29^{\circ} \mathrm{C}\right.$ and $71{ }^{\circ} \mathrm{C}$ ) and water resistant and never require recalibration. The calibrated velocity range is 0 to 5000 fpm $\left(0\right.$ to $\left.25 \mathrm{~m} \mathrm{~s}^{-1}\right)$ and the manufacturers rated installed airflow accuracy is $2 \%$ to $3 \%$ of the reading.

In the experiments, we used L2 upstream of MT2. With a nominal $2 \mathrm{ft}$ by $2 \mathrm{ft}(0.6 \mathrm{~m}$ by $0.6 \mathrm{~m})$ louver, per the manufacturers recommendations, we used two probes with three sensors per probe. In this type of installation, the manufacturer recommends a minimum 14 inch $(0.36 \mathrm{~m})$ undisturbed airflow path between the louver and damper with installation of the sensors 12 inch $(0.30 \mathrm{~m})$ downstream of the louvers and as close as 2 in $(5 \mathrm{~cm})$ upstream of the OA damper. When a longer undisturbed airflow path is available, the 
manufacturer recommends installation of probes two-thirds of the distance downstream of upstream component (louver). In our tests, the distance between the downstream edge of the louver and upstream edge of the fully open damper was 23 inch $(58 \mathrm{~cm})$. Probes were located 15.5 inch $(39 \mathrm{~cm})$ downstream of downstream edge of the louver and $7.5 \mathrm{inch}(19 \mathrm{~cm})$ upstream of upstream edge of the fully open damper. Probes were installed one-third and two-thirds of the distance across the duct, horizontally in some tests and vertically in other tests, and installed at other locations to determine how location affected accuracy. The velocity displayed by MT2 was a constant multiple of the MT2 voltage output signal. To calculate the air flow rate, we recorded the output voltage, calculated the velocity (which was more convenient than manually reading the displayed velocity), and then multiplied this velocity by the $4 \mathrm{ft}^{2}$ $\left(0.37 \mathrm{~m}^{2}\right)$ cross sectional area of the duct located between the louvers and OA damper. In the tests, we used Louver 2 upstream of MT2.

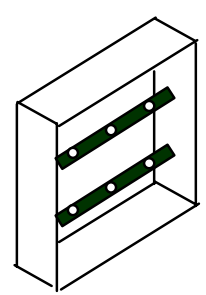

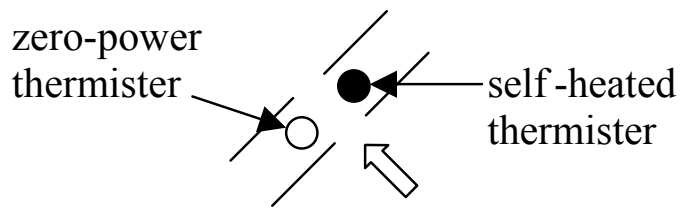

Airflow

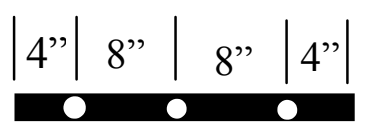

Figure 4. Illustration of measurement technology 2 (MT2). The left side of figure shows two probes in a section of duct that would typically be downstream of outdoor air louvers and upstream of outdoor air dampers. The central diagram shows a detail of a sensor within a probe. The right diagram shows the locations of sensors in a probe.

Measurement technology number 3 (MT3), illustrated in Figure 5 uses special static pressure tap at the outdoor face of the OA inlet and another type of static pressure tap downstream of the OA louver to sense the pressure drop across the louver. The outdoor pressure tap, mounted on the inlet face of the louver system appears to be designed to provide a pressure signal unaffected by wind direction. The pressure tap placed downstream of the louver, called an "inlet airflow sensor" is a 0.5 inch $(1.3 \mathrm{~cm})$ diameter 5 inch $(13 \mathrm{~cm})$ long cylinder with a 0.8 inch $(2 \mathrm{~cm})$ long sintered metal end that is inserted through a duct wall into the airstream. We presume that this tap is designed to provide a reliable measure of static pressure in the turbulent airstream located downstream of a louver. The full MT3 system comes with a pressure transducer, temperature sensor to enable control for air density, electronics, and a digital display. The system is designed for OA velocity ranges of either 150 to $600 \mathrm{fpm}\left(0.8\right.$ to $\left.3.0 \mathrm{~m} \mathrm{~s}^{-1}\right)$ or 250 to $1000 \mathrm{fpm}$ ( 1.3 to $5.1 \mathrm{~m} \mathrm{~s}^{-1}$ ) and has a rated accuracy of $\pm 5 \%$ of the reading. The relationship of measured pressure drop to OA flow rate will vary with the design of the louver and must therefore be determined via a factory or field-based determination of this relationship. We did not use the manufacturer's electronics or pressure sensor -- we used our research grade pressure transducer to measure the pressure difference. Thus, our tests only determined whether the OA flow rate could be determined by measuring the pressure difference across an OA inlet louver using the pressure taps provided. Because field based measurements of OA flow- pressure drop relationship may be impractical, we assumed that in practice a user would estimate OA flow rates from the measured pressure drops across the louvers and the pressure drop velocity data provided by the louver manufacturers. We installed the "inlet airflow sensor" through the duct side wall at various locations. For some tests, in place of the inlet airflow sensor we used static pressure taps in the walls of the duct downstream of the louvers or the static taps of Pitot-static tubes installed downstream of the louver. MT3 was tested using all three types of louvers placed upstream. 


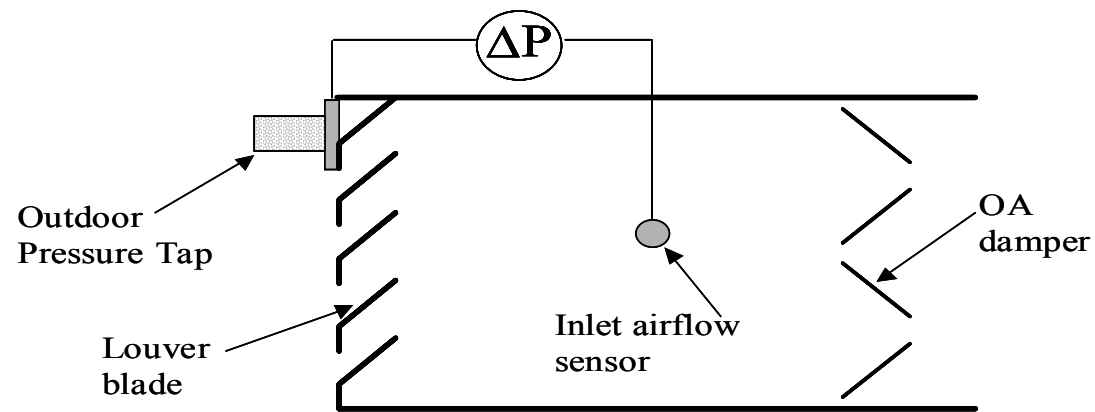

Figure 5. Schematic illustration of MT3

Measurement technology number 4 (MT4), illustrated in Figure 6, contains an airflow straightener upsteam of a set of airflow monitoring blades, followed by a section of straight ductwork and then an OA damper. The airflow straightener is constructed of $3 / 8$ in $(0.95 \mathrm{~cm})$ aluminum honeycomb. The airflow monitoring blades are identical ${ }^{11}$ to those used in MT1. The basic measurement concept appears to be to straighten and condition the airflow with the airflow straightener, determine an average velocity from a pressure signal obtained from the airflow monitoring blades, and provide some straight duct downstream of the airflow monitoring blades to isolate the blades from airflow disturbances at the OA damper. The manufacturers recommended velocity range is 400 to $5000 \mathrm{fpm}$ ( 2 to $25 \mathrm{~m} / \mathrm{s}$ ) which correspond to 1600 to $20,000 \mathrm{cfm}(760$ to $9,400 \mathrm{~L} / \mathrm{s})$ for a $2 \mathrm{ft}$ by $2 \mathrm{ft}(0.6 \mathrm{~m}$ by $0.6 \mathrm{~m})$ duct. The rated accuracy is $\pm 3 \%$ for a set of standard test conditions that include an upstream section of straight duct. In our tests, the unit was installed immediately downstream of L1. However, we modified Louver 1 slightly by removing some plates that blocked the periphery of the outlet plane, so that the air passage at the outlet of the louver better matched dimensions of the duct system and airflow straightener. The unit can be supplied with a pressure transducer, actuators, and controls; however, we evaluated none of these elements. We used our research grade pressure transducer and manipulated the damper position manually.

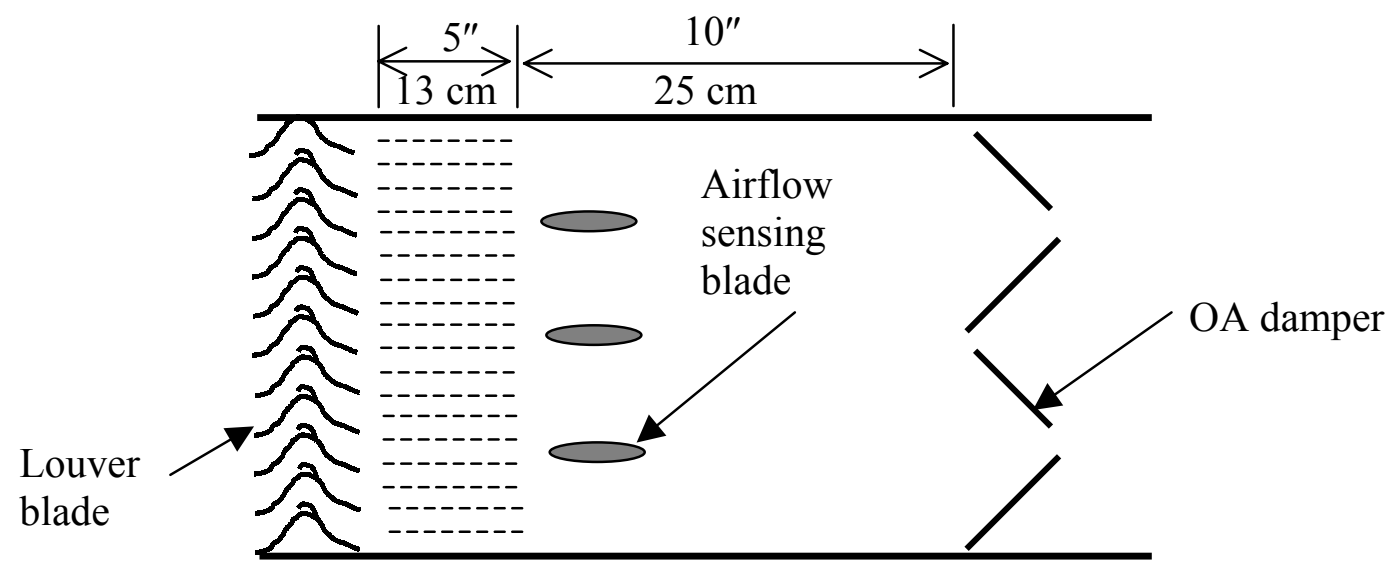

Figure 6. Schematic illustration of MT4 installed in the OA inlet section of a HVAC system.

\footnotetext{
${ }^{11}$ The same manufacturer produces MT1 and MT4.
} 
Measurement technology number 5 (MT5) is a prototype based on a concept developed at LBNL ${ }^{12}$. Our goal was to develop a measurement system that had a larger pressure signal than commercially available measurement technologies, while maintaining acceptable pressure drops. The larger pressure signal is desired to enable reasonable accuracy in measurement of OA flow rates using standard pressure transducers. A larger pressure signal would be particularly advantageous when HVAC systems have economizer controls and are providing minimum outdoor air, which may be $20 \%$ of the maximum flow rate of OA.. The low air speeds that occur at the inlet of HVAC systems under these conditions leads to pressure signals that are often to small for accurate measurements with many standard pressure transducers.

Our design is a variant of the venturi flow meter, which is a type of flow meter that provides a high ratio of pressure signal to pressure loss. To the best of our knowledge, all existing venturi flow meter designs have a cylindrical geometry and are used in piping systems. Because venturi flow meters have a smooth contraction in the air flow passage upstream of the plane of minimum cross sectional area (called the throat), and also have a long smooth diverging cone downstream of the throat, their pressure signal can be two or three times larger that their pressure loss. In other words, the design of the venturi flow meter enables a transition between static and dynamic pressures with low total pressure losses. Our design of an OA flow measurement technology mimics that in a venturi flow meter but with the airflow passage contracting in only one dimension, thus, we apply the term one-dimensional (1D) venturi. In addition, a series of airflow passages, each with a 1D venturi, are used in parallel and the spacing at the inlet of these passages is matched to the spacing of the louver blades at the outlet of Louver 1. Thus, the airflow passages of the louver become the airflow passes of MT5, which reduces pressure drops (exit and entrance losses) compared to a design with a section of duct between the louver and measurement system. In addition, because the direction of airflow out of the louver is aligned with the direction of airflow desired at the inlet of the flow meter, non-uniform velocities in the flow meter are diminished which improves measurement accuracy.

Figure 7 provides an illustration of MT5. For illustrative purposes we show only three airflow passages, each with a $1 \mathrm{D}$ venturi, while the actual flow meter has 14 airflow passages. In the figure, the passage width has been exaggerated relative to the length. This passage width of prototype was designed to match the 1.5 in $(3.8 \mathrm{~cm})$ spacing of the blades of Louver 1, which is an existing product. However, an ideal design would have a larger number of more closely spaced passages to enable the length of the flow meter to be reduced. For example, by reducing the width of the inlet passages to 0.5 in $(1.2 \mathrm{~cm})$, the length of the flow meter would be reduced to 6 in $(15 \mathrm{~cm})$. The width at the throat is $0.3 \mathrm{in} .(0.8 \mathrm{~cm})$, thus, the air velocity increases by a factor of five. Maintaining angles $\theta$ and $\alpha$ not greater than approximately $11^{\circ}$ and $7.5^{\circ}$ is a key to maintaining low pressure drops. If the flow meter is to be cost effective, it must be made inexpensively, for example from cast aluminum or molded plastic that meets flame spread and smoke generation requirements. Because of the high cost of producing the mold, we constructed the prototype from shaped sheets of sheet metal. The pressure signal in the prototype is the static pressure in the straight airflow passages upstream of the contraction minus the static pressures at the throats of the passages, although other types of pressure tap systems could be used to measure the air speed where the airflow passage has a minimum width.

\footnotetext{
${ }^{12}$ A provisional patent application has been filed for MT5
} 


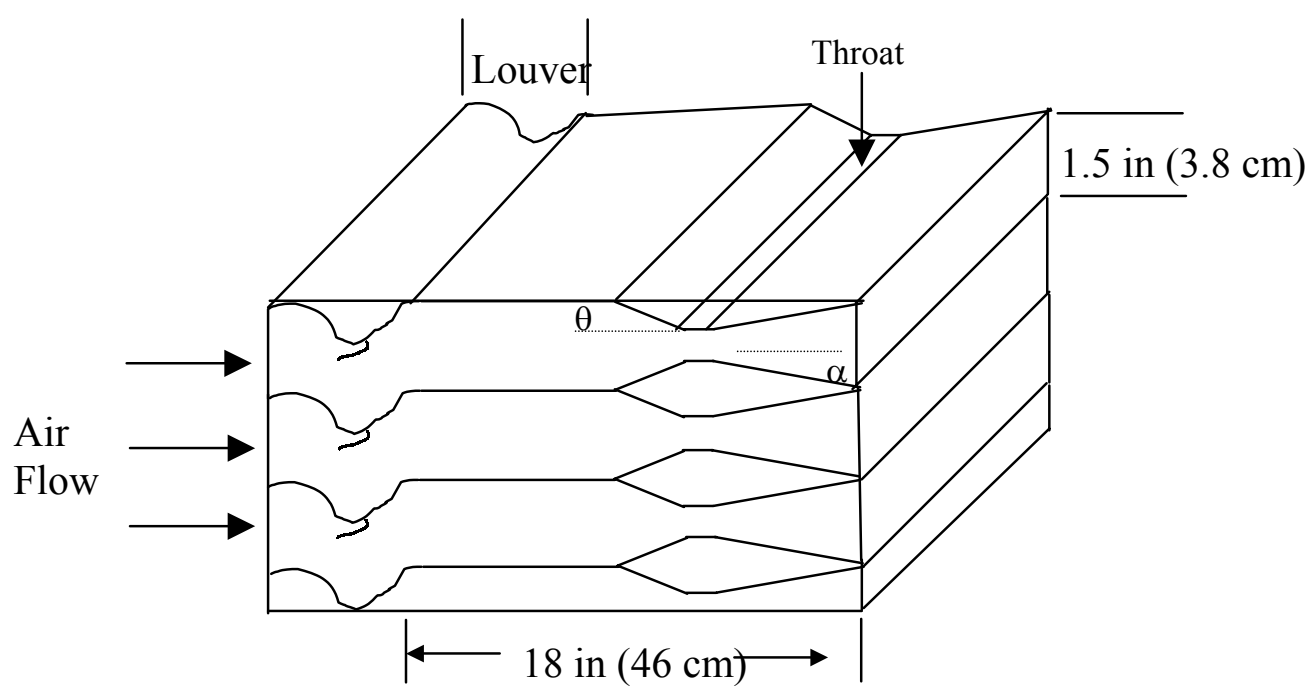

Figure 7. Illustration of MT5.

\section{Results}

\section{Measurement Technology 1}

Figure 8 shows the accuracy (\%error) of MT1 plotted versus the reference (i.e., "true") OA flow rate. The figure includes results of tests with a range of $\% \mathrm{OA}$ (from $10 \%$ to $100 \%$ ) and with a range of OA damper positions. Figure 9 provides the measured pressure signal from the airflow sensor blades of MT1. With our research-grade pressure transducer used to measure this pressure difference, MT1 is accurate within approximately $\pm 20 \%$ for outdoor air flow rates ${ }^{13}$ exceeding approximately $250 \mathrm{cfm}\left(0.12 \mathrm{~m}^{3} \mathrm{~s}^{-1}\right)$. In actual applications, the pressure transducer normally used in conjunction with MT1 will be less accurate (and also less expensive) than our research-grade pressure transducer. Therefore, for three OA flow rates, Figure 8 includes sets of error bars illustrating the expected errors in OA flow rates measured with MT1 with errors in differential pressure measurement of \pm 0.004 and \pm 0.01 inch water $( \pm 1 \mathrm{~Pa}$ and \pm $2 \mathrm{~Pa}$ ), which are assumed to be more typical of the errors that occur with the electronic pressure transducers commonly used in field settings. With an error in pressure measurement of $\pm 0.01 \mathrm{IWG} \mathrm{Pa}( \pm$ $2 \mathrm{~Pa}$ ), the corresponding error in OA flow rate is as high as $100 \%$ at $20 \%$ of the manufacturers recommended maximum rate of flow through the louver. If pressure measurement errors can be limited to \pm 0.004 inch water $( \pm 1 \mathrm{~Pa})$, the maximum error in outdoor air flow rate measurement is about $-20 \%$ to $+30 \%$ with a flow rate equal to $20 \%$ the manufacturers maximum recommended flow rate. As OA flow rates increase, the errors from inaccurate pressure measurements will decrease dramatically. Based on a more detailed examination of the test data, the accuracy of MT1 appeared to be nearly independent of both \%OA (i.e., the rate of air recirculation) and the degree of opening of the OA damper.

\footnotetext{
${ }^{13}$ To convert the flow rates in this document to the nominal air velocities upstream or downstream of louvers divide cfm values by $4 \mathrm{ft}^{2}$ or L/s values by $0.37 \mathrm{~m}^{2}$.
} 


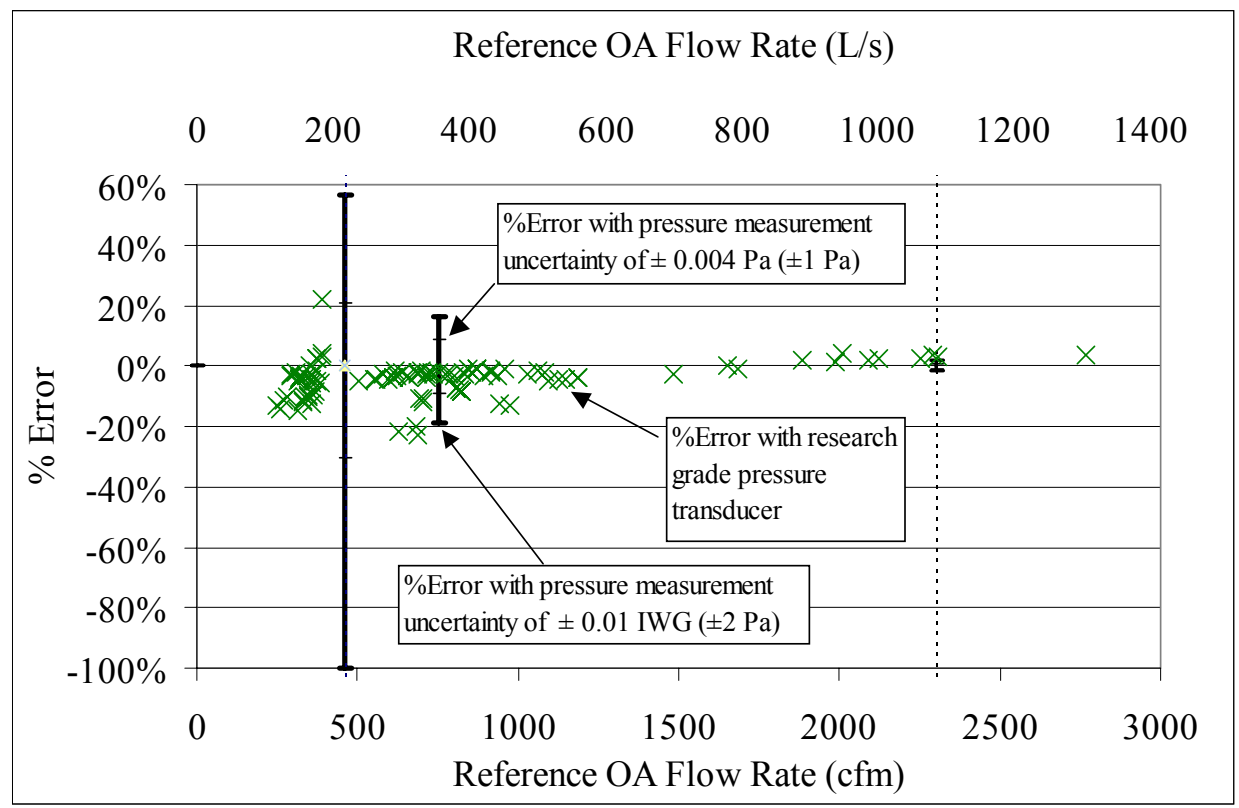

Figure 8. Accuracy of MT1 versus reference OA flow rate. The dashed vertical line marks $100 \%$ of the manufacturer's recommended rate of flow through the louver and the left-most set of error bars is positioned at $20 \%$ of the manufacturer's recommended rate of flow through the louver.

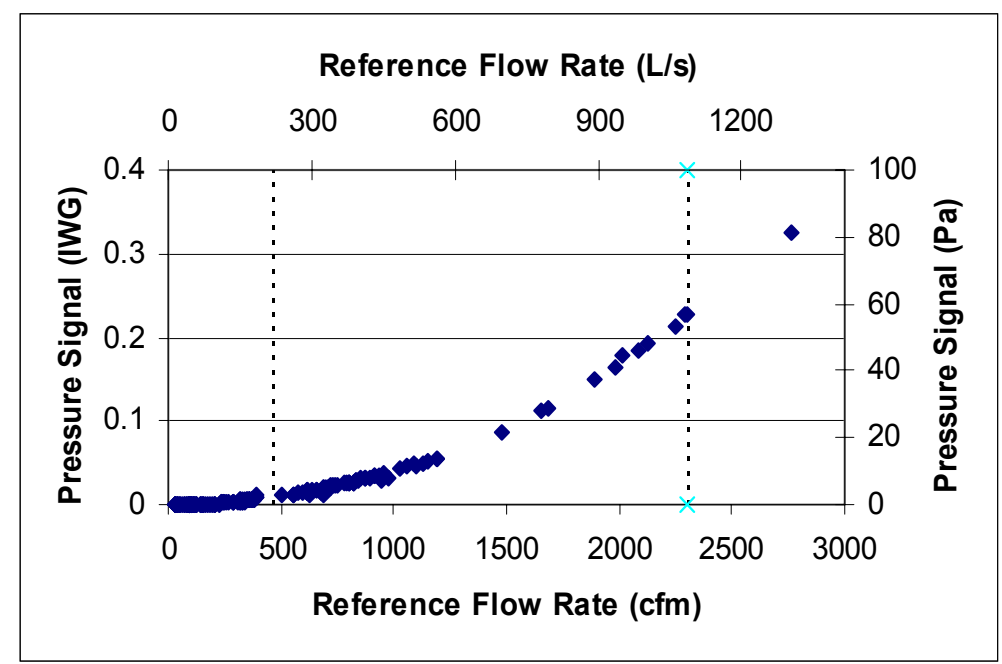

Figure 9. Pressure signal of MT1 versus reference OA flow rate.

Measurement Technology 2

Table 3 shows the probe configurations (horizontal or vertical probes, probe locations) used in tests of MT2. For each probe configuration, Figure 10 plots the OA flow rate determined from MT2 (i.e., the indicated air velocity multiplied by the duct cross sectional area) versus the reference OA flow rate. The legend of the table shows the slopes obtained from linear regression fits to the data and provides the squares of the associated correlation coefficients. For each probe configuration, the OA flow rate 
indicated by MT2 varies approximately linearly with reference OA flow rate, with only modest scatter. Thus, if an accurate field-based calibration can be performed, MT2 should yield accurate measurements of OA flow rates. However, when we simply multiply the air velocity from MT2 by the cross sectional area of the duct section downstream of the louver, the OA flow rates indicated by MT2 can differ substantially from the reference $\mathrm{OA}$ flow rates. The slopes for probe configurations with horizontal probes are $0.68,0.70$, and 0.77 , indicating that OA flow rates from MT2 are $32 \%, 30 \%$, and $23 \%$ less than reference OA flow rates. With probes installed vertically, the flow rates indicated by MT2 were more than $100 \%$ higher than the reference OA flow rates (see discussion section).

Table 3. Probe configurations for tests of MT2

\begin{tabular}{|c|c|c|c|}
\hline $\begin{array}{c}\text { Probe } \\
\text { Configuration } \\
\text { Code }\end{array}$ & $\begin{array}{c}\text { Horizontal (H) or } \\
\text { Vertical (V) } \\
\text { Probes }\end{array}$ & Probe Locations & $\begin{array}{c}\text { Recirc- } \\
\text { ulation }\end{array}$ \\
\hline PC1 & H & $8 \& 16$ in $(20 \& 41 \mathrm{~cm})$ from top of duct & No \\
\hline PC2 & H & 6 and 14 in $(15 \& 36 \mathrm{~cm})$ from top of duct & No \\
\hline PC3 & H & 6 and 14 in $(15 \& 36 \mathrm{~cm})$ from top of duct & Yes \\
\hline PC4 & V & 8 and 16 in $(20 \& 41 \mathrm{~cm})$ from side of duct & No \\
\hline
\end{tabular}

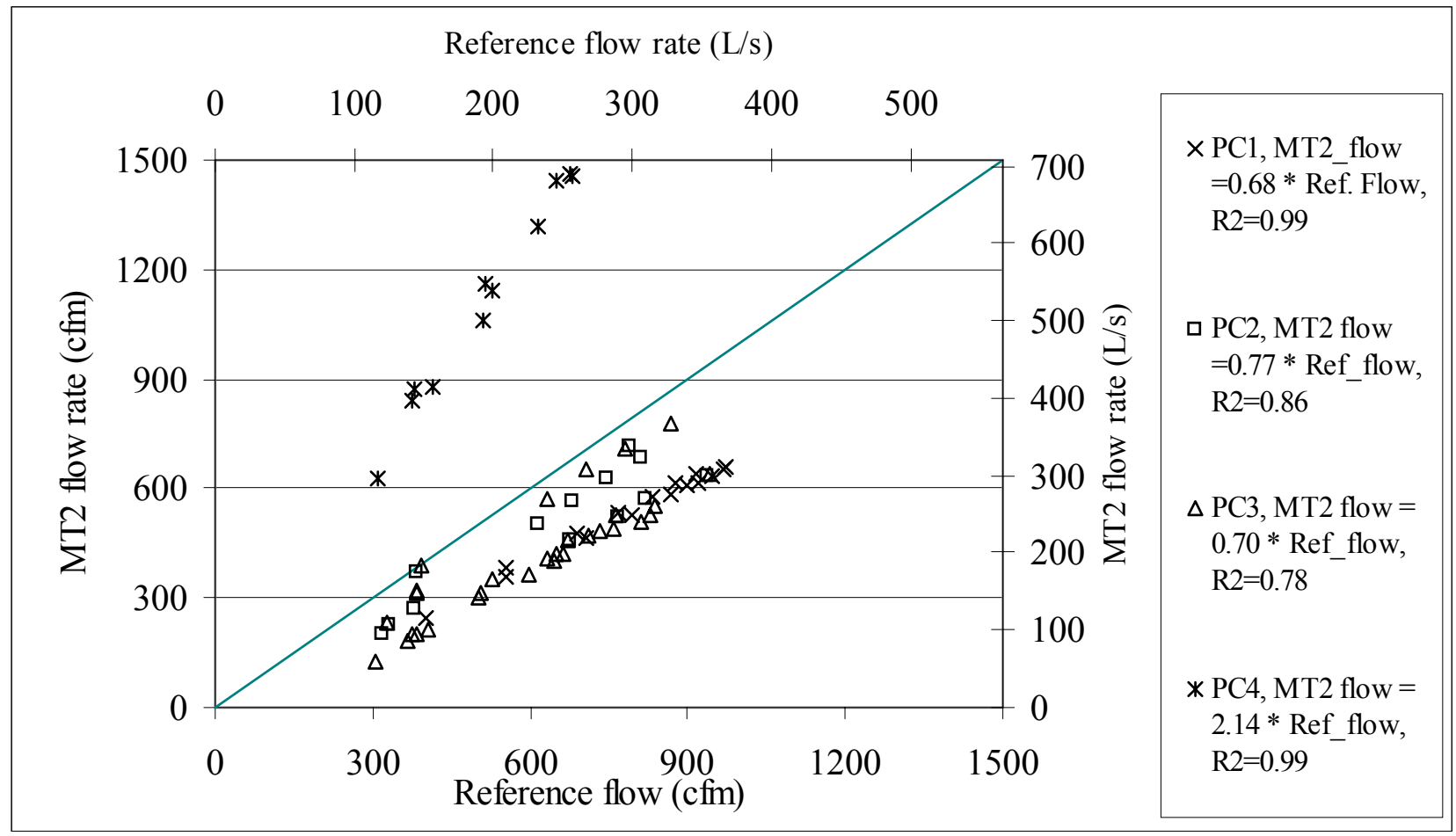

Figure 10. Results of tests of MT2

Measurement Technology 3

Figure 11 shows the results of using MT3 in conjunction with L1. The horizontal axis is the reference OA flow rate and the vertical axis is the OA flow rate predicted based on the measured pressure drop 
across L1 and the louver manufacturer's pressures versus flow rate data ${ }^{14}$ for L1. The figure shows results with the inlet airflow sensor of MT3 installed at two locations downstream of L1. The first location was 7.5 inch $(19 \mathrm{~cm})$ downstream of the downstream edge of L1, 12 inch $(30.5 \mathrm{~cm})$ from the top of the duct, inserted through a vertical duct wall. The second location was 20 inch $(51 \mathrm{~cm})$ further downstream from L1 and 8 inch $(20 \mathrm{~cm})$ from the top of the duct, inserted through he same duct wall. With these two tap locations, the predicted flow rates were 1.20 and 1.24 times the reference flow rates, respectively, and the predicted and reference flow rates were well correlated $\left(\mathrm{R}^{2}=0.99\right.$ to 1.00$)$. Thus, without reliance on a field-based calibration, MT3 used with L1 should yield OA flow rates accurate within approximately $20 \%$ when the pressure signal is large enough to be measured accurately. For comparison, Figure 11 also shows results obtained with the pressure downstream of L1 based on the average of downstream pressures from three static pressure taps located on the duct top wall and two side walls downstream of L1. In this case, the predicted flow rate was 1.05 times the reference flow rate; however, the improvement in accuracy may be fortuitous because the measured pressure drop varied substantially among the three locations.

The results depicted in Figure 11 were obtained using our research grade pressure transducer. At 20\% of the maximum recommended air flow rates through the L1, i.e., at a flow rate of $460 \mathrm{cfm}(270 \mathrm{~L} / \mathrm{s})$, the measured pressure drops across L1 was only about 0.01 inch water $(2.5 \mathrm{~Pa})$. With this low OA flow rate, the errors in determination of OA flow rate could easily exceed $50 \%$ unless a very accurate pressure transducer was used to make the pressure measurements.

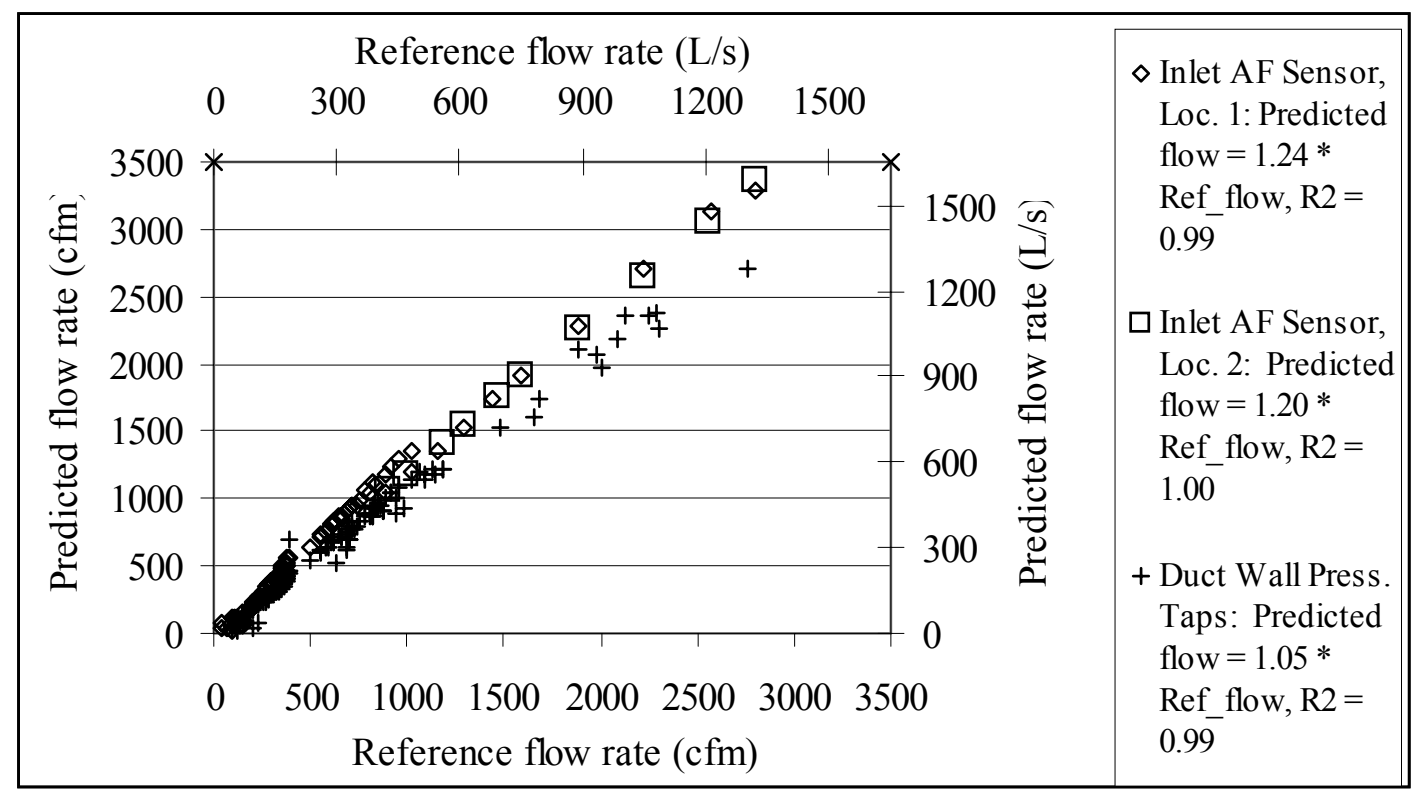

Figure 11. Relationship of reference flow rate to flow rate predicted using MT3 plus the manufacturer's pressure versus flow rate data for L1. Two of the data series represent data collected with an inlet airflow sensor of MT3 located downstream of L1 at two different locations. The third data series represents data collected with the pressure downstream of L1 based on the average from pressure taps in three duct walls.

\footnotetext{
${ }^{14}$ Actually, the louver manufacturer provides data graphically on pressure drop versus free-area velocity. We multiplied the free area velocity by the free area of L1 and curve fit the data with a power equation. The resulting equation was $\left.\mathrm{cfm}=311(\mathrm{IWG} * 250)^{\wedge} 0.4978\right)$, with an $\mathrm{R}^{2}=1.00$.
} 
The results of using MT3 in conjunction with L2 are shown in Figure 12. The measured data for L2 reflect conditions with 5\% to $100 \%$ OA. To perform the measurements with L2, we used the "inlet airflow sensors" of MT3 located at two positions downstream of the louver. The first location was 4.5 in $(11.4 \mathrm{~cm})$ downstream of the downstream edge of the louver and 12 in $(30.5 \mathrm{~cm})$ from the top of the duct, inserted through a side duct wall. The second location was 20 in $(51 \mathrm{~cm})$ further downstream from the louver and 8 in $(20 \mathrm{~cm})$ from the top of the duct. The data points from these two probe locations fall on the same curve and are not distinguished on the figure. The predicted flow rate ${ }^{15}$ was 1.28 times the reference flow rate, and the predicted and reference flow rates are well correlated $\left(\mathrm{R}^{2}=1.00\right)$. Thus, without reliance on a field-based calibration, MT3 used with L2 should yield OA flow rates accurate within approximately $28 \%$ when the pressure signal can be accurately measured. At $20 \%$ of the maximum recommended airflow through the louver, the pressure signal for determining OA flow rate is only about $0.005 \mathrm{IWG}(1 \mathrm{~Pa})$, which is too small for accurate measurements with the pressure transducers and procedures used in buildings.

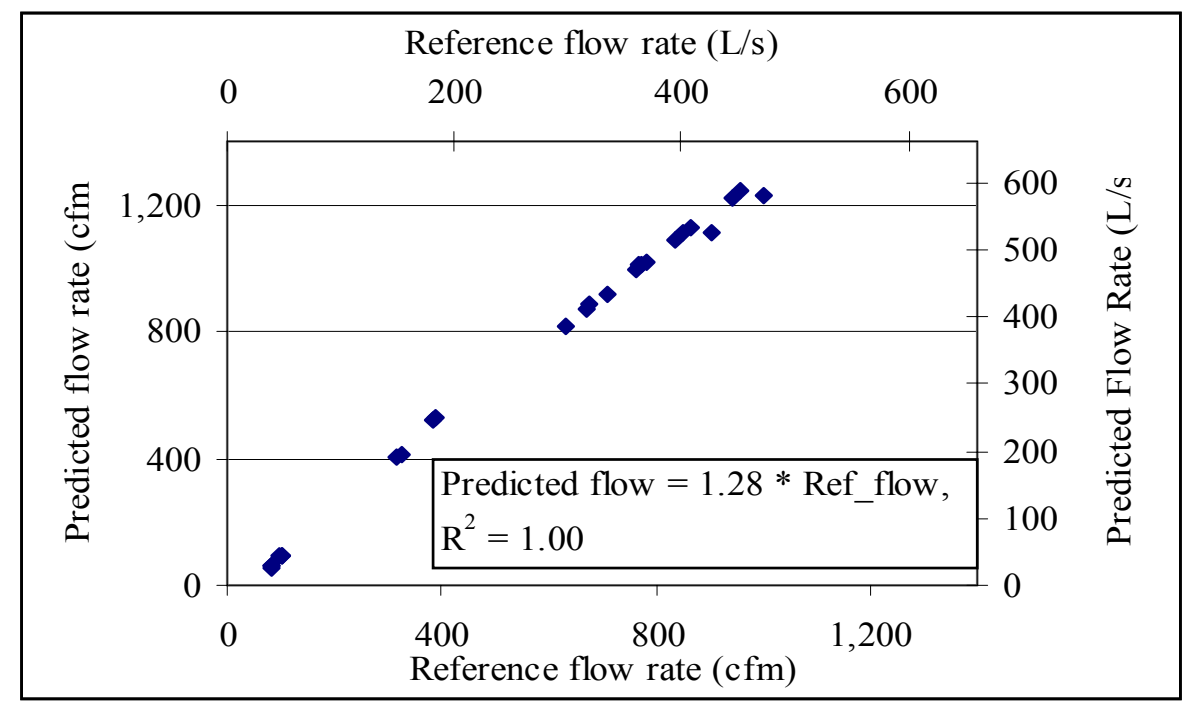

Figure 12. Relationship of reference flow rate to flow rate predicted using MT3 plus the louver manufacturer's pressure versus flow rate data for L2.

The tests of MT3 with L3 were performed without any recirculation and with a set of three Pitot-static tubes used in place of the inlet airflow sensor as the static pressure sensor located downstream of L3. The distance between the downstream edge of the louver and the upstream edge of fully open blades of the OA damper was $2 \mathrm{ft}(0.6 \mathrm{~m})$ and the Pitot-static tubes were installed halfway between the louver and the damper. The predicted flow rates ${ }^{16}$ were 1.2 times the reference flow rates (Figure 13) and again the predicted and reference flow rates were very well correlated. Thus, without reliance on a field-based calibration, MT3 in conjunction with L3 should yield OA flow rates accurate within approximately $20 \%$ when the pressure signal is large enough to be measured accurately. At $20 \%$ of the maximum recommended airflow through the louver, the pressure signal for determining OA flow rate is less than $0.01 \mathrm{IWG}(2.5 \mathrm{~Pa})$, which again is too small for accurate measurement ${ }^{17}$.

\footnotetext{
${ }^{15}$ The predicted flow rate was based on a curve fit to manufacturer's pressure drop versus velocity data for L2. The resulting equation was $\mathrm{cfm}=130 *(\mathrm{IWG} * 250)^{\wedge} 0.4729$.

${ }^{16}$ The predicted flow rate was based on a curve fit to manufacturer's pressure drop versus velocity data for L3. The resulting equation was $\mathrm{cfm}=219 *(\mathrm{IWG} * 250)^{\wedge} 0.515$.

${ }^{17}$ With our estimated uncertainty in pressure measurements of $2 \mathrm{~Pa}$, errors could be $100 \%$
} 


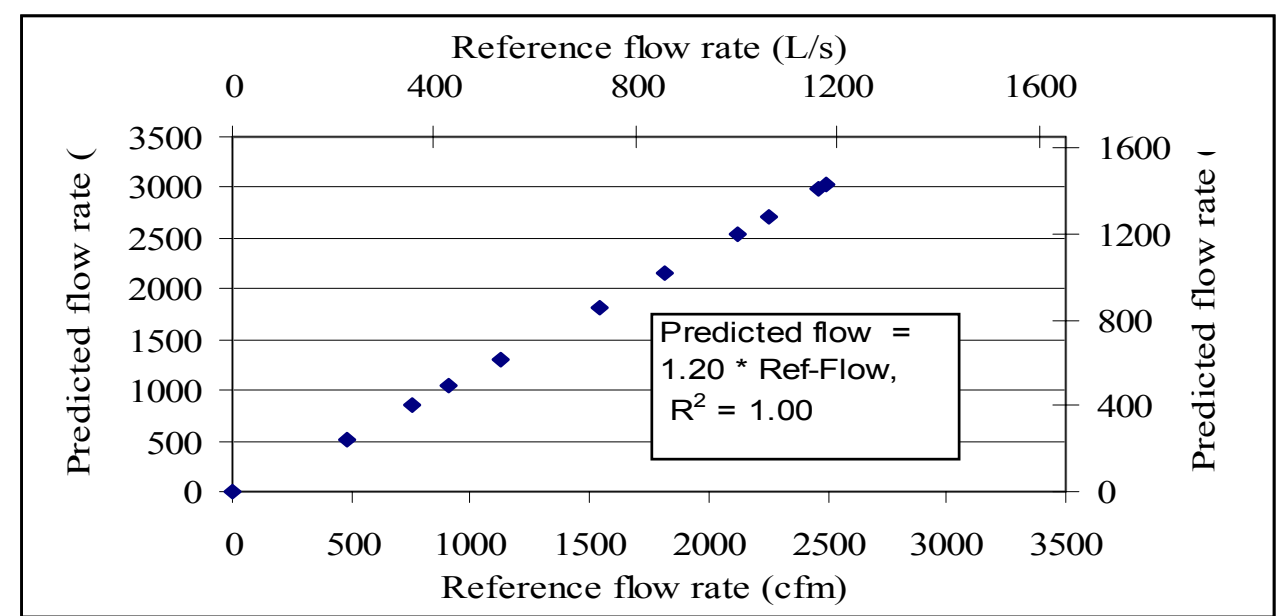

Figure 13. Relationship of reference flow rate to flow rate predicted from the measured pressure drop across L3 plus the louver manufacturer's pressure versus flow rate data for L3.

\section{Measurement Technology 4}

The relationship of pressure signal with reference flow rate for MT4 when placed downstream of L1 is shown in Figure 14. There is a smooth well-defined relationship of pressure signal with flow rate. The pressure signal becomes very small, less than approximately $0.01 \mathrm{IWG}(2.5 \mathrm{~Pa})$, when the flow rate is less than $1000 \mathrm{cfm}(470 \mathrm{~L} / \mathrm{s})$. Therefore accurate measurements of flow rate will only be possible when the rates of airflow through the $\mathrm{L} 1$ are above approximately $50 \%$ of the maximum recommenced flow rate through L1. Figure 15 shows the \%error in the flow rate measurement versus reference flow rate. Using our research grade pressure transducer to measure the pressure signal, the error is less than $\pm 10 \%$ for flow rates exceeding $1000 \mathrm{cfm},(470 \mathrm{~L} / \mathrm{s})$. All of the data points indicating an error larger than $\pm 10 \%$ are from tests with a pressure signal smaller than $0.01 \mathrm{IWG}(2.5 \mathrm{~Pa})$. The tests conditions included values of \%OA ranging from $5 \%$ to $100 \%$ and an examination of test data indicates that the measurement error was unrelated to \%OA. The manufacturer's minimum recommended flow rate for MT4 is $1600 \mathrm{cfm}$ (760 $\mathrm{L} / \mathrm{s}$ ); thus, for flow rates in the manufacturer's recommended range the \%error using our research grade pressure transducer was less than $10 \%$. At $1600 \mathrm{cfm}$, the pressure signal was approximately $0.03 \mathrm{IWG}$ $(7.5 \mathrm{~Pa})$. If the pressure measurement uncertainty with a practical pressure transducer was $0.01 \mathrm{IWG}$ (2 $\mathrm{Pa}$ ), the associated uncertainty range in the measurement of $\mathrm{OA}$ flow rate would be $-10 \%$ to $+16 \%$.

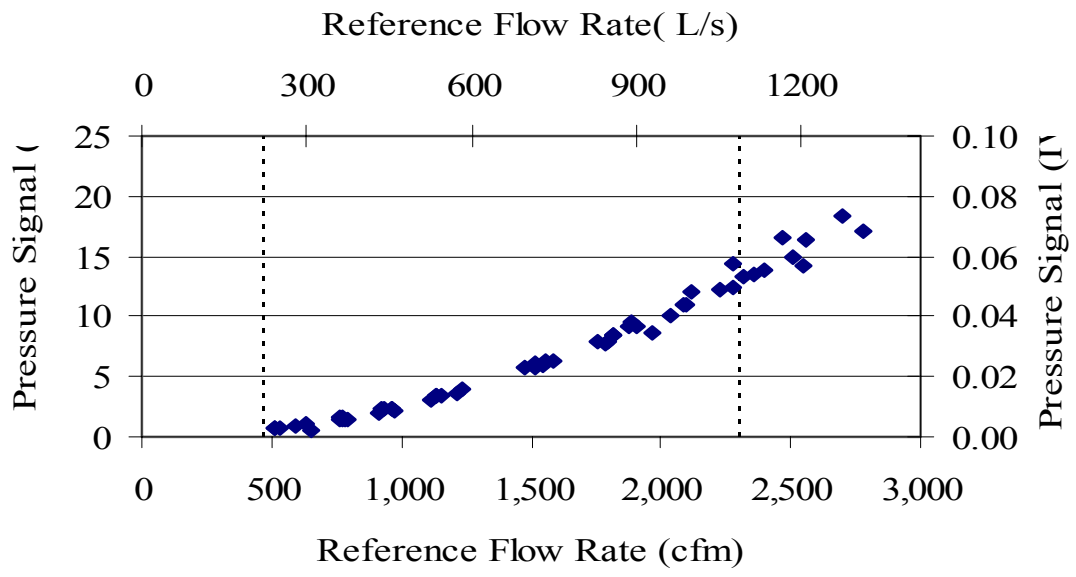

Figure 14. Pressure signal of MT4 versus reference air flow rate, with MT4 installed downstream of L1. The dashed vertical lines mark $100 \%$ and $20 \%$ of the maximum recommended rate of flow through L1. 


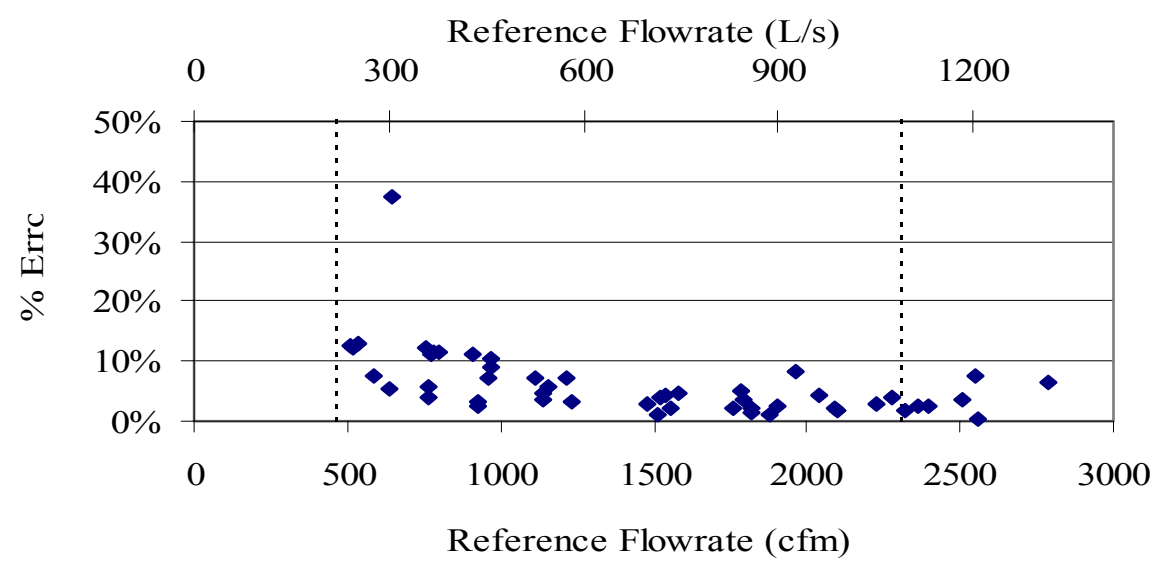

Figure 15. Percent error in measurements of flow rate with MT4 installed downstream of L1 versus reference flow rate. The dashed vertical lines mark $100 \%$ and $20 \%$ of the maximum recommended rate of flow through L1. All of the data points indicating an error larger than $\pm 10 \%$ are from tests with a pressure signal smaller than 0.01 IWG (2.5 Pa).

\section{Measurement Technology 5}

Figure 16 provides the output pressure signal of MT5 versus the reference OA flow rate. In the tests, the $\% \mathrm{OA}$ ranged from $17 \%$ to $100 \%$. The equations

$$
\begin{aligned}
& C F M=3340 \sqrt{I W G} \\
& L / s=99.6 \sqrt{P a}
\end{aligned}
$$

fit the data within a few percent, where IWG and $\mathrm{Pa}$ are the measured pressure signals in units of inches of water and Pascal, respectively.

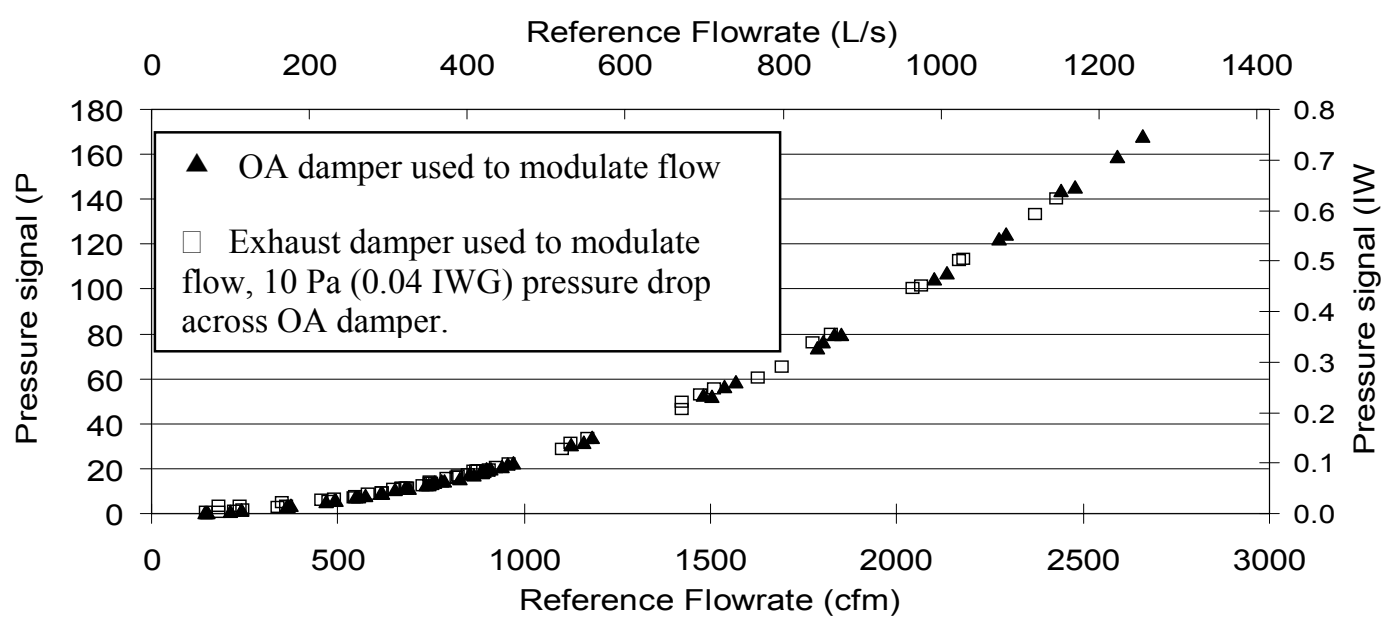

Figure 16. Pressure signal versus full range of reference flow rate for MT5.

Figure 17 provides an expanded view of the device performance with low reference OA flow rates. The minimum expected pressure signal is about $0.024 \mathrm{IWG}(6 \mathrm{~Pa})$ assuming the HVAC system has a 
minimum OA flow rate that is $20 \%$ of the maximum OA flow rate and that the maximum OA flow produces the maximum recommended air velocity in the upstream louver. Because MT5 is a first prototype, not a commercial product, there is no manufacturer's reference calibration curve, thus, a figure indicating percent error cannot be provided. However, it is clear that the output pressure signal varies smoothly with OA flow rate and that air recirculation does not affect MT5 performance as long as a 0.04 IWG (10 Pa) pressure drop is maintained across the OA damper. Using equations 1 or 2 , we can estimate the error in OA flow rate measurement caused by errors in pressure signal measurement. $\mathrm{A} \pm 0.01$ IWG $( \pm 2 \mathrm{~Pa}$ ) pressure measurement error would lead to errors in OA flow rate measurement of approximately $\pm 19 \%$ if the minimum OA flow rate is $20 \%$ of the maximum OA flow rate. The associated errors decrease rapidly as the OA flow rate increases. For example, if the minimum OA flow rate is $25 \%$ of the maximum OA flow rate, a $\pm 0.01 \mathrm{IWG}( \pm 2 \mathrm{~Pa}$ ) pressure measurement error would lead to errors in OA flow rate measurement of approximately $\pm 8 \%$.

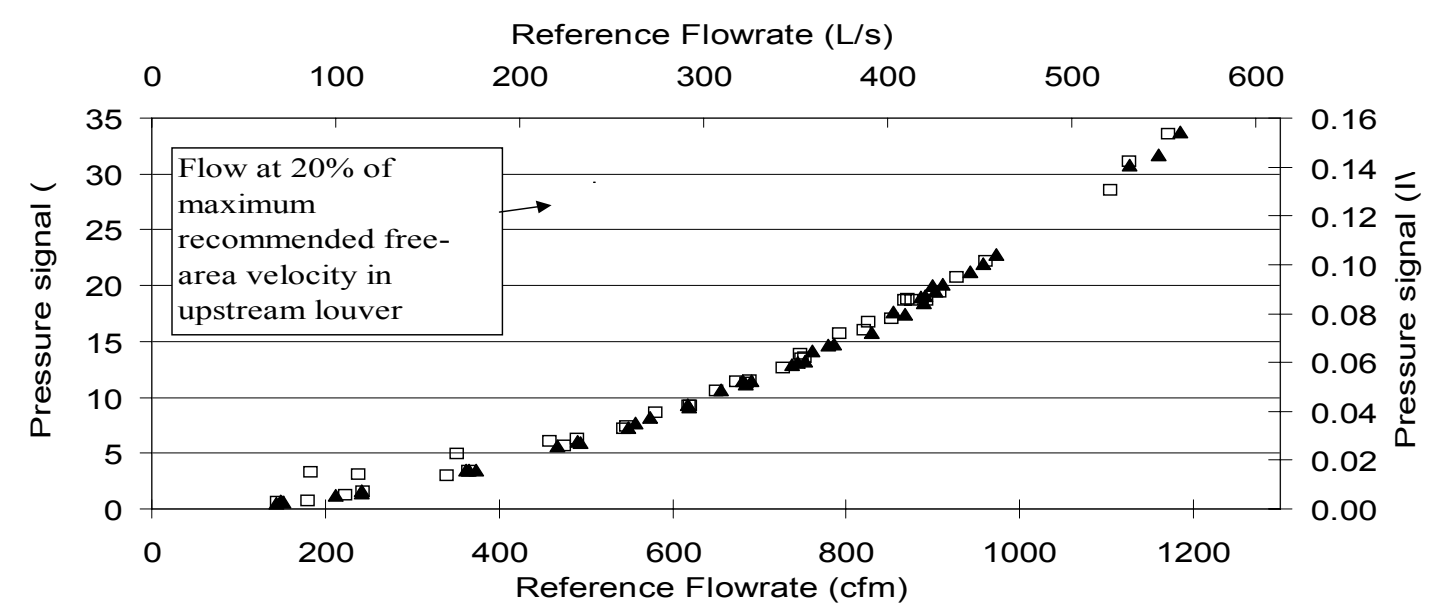

Figure 17. Pressure signal versus lower range of reference flow rates for MT5, data marker styles are defined in Figure 16.

Figure 18 provides a plot of the airstream pressure drop (permanent pressure loss) from use of MT5 as a fraction of the pressure signal that indicates OA flow rate. The measurements were made without a louver upstream of the OA measurement device. The pressure drop is $60 \%$ to $80 \%$ of the pressure signal which means that there is a $20 \%$ to $40 \%$ pressure recovery. The amount of pressure drop at high OA flow rates is most important and with high flow rates, the pressure drop is approximately $60 \%$ of the pressure signal.

MT5 was designed to be used as an integral unit with L1, in part, to further reduce pressure drops. If the inlet of MT5 was located some distance downstream of the outlet of L1, we would expect pressure losses associated with the air exiting the louver and then entering MT5. However, in our design, the airflow channels of MT5 are an extension of the outlet of L1. Thus, the net pressure drop of MT5 is less than indicated in Figures 16 through 18. The net pressure drop of MT5 was estimated ${ }^{18}$ by measuring the pressure drop of the louver-MT5 system and subtracting the pressure drop of just the louver ${ }^{19}$. We then

\footnotetext{
${ }^{18}$ Because we did not have experimental data at precisely the same flow rates from the two sets of measurements, we used the curve fitting routines of a spreadsheet program to generate equations for pressure-flow rate curves and then computed the net pressure drop using the equations. The correlation coefficients for the curve fits exceeded 0.99 .

${ }^{19}$ We used the pressure drop of an unmodified louver, which is likely to slightly higher than the pressure drop of the
} 
divided this net pressure drop by the pressure signal of MT5 and used the results to generate Figure 19. This figure show that the net pressure drop of MT5, when integrated with L1, is approximately $35 \%$ to $60 \%$ of the pressure signal used to determine OA flow rate. At high flow rates, where pressure drops are most important, the net pressure drop is $35 \%$ to $40 \%$ of the pressure signal. Thus, at the maximum recommended rate of air flow through the upstream louver $(2300 \mathrm{cfm}$ or $1090 \mathrm{~L} / \mathrm{s})$, the net pressure drop is approximately 0.17 IWG $(43 \mathrm{~Pa})$.

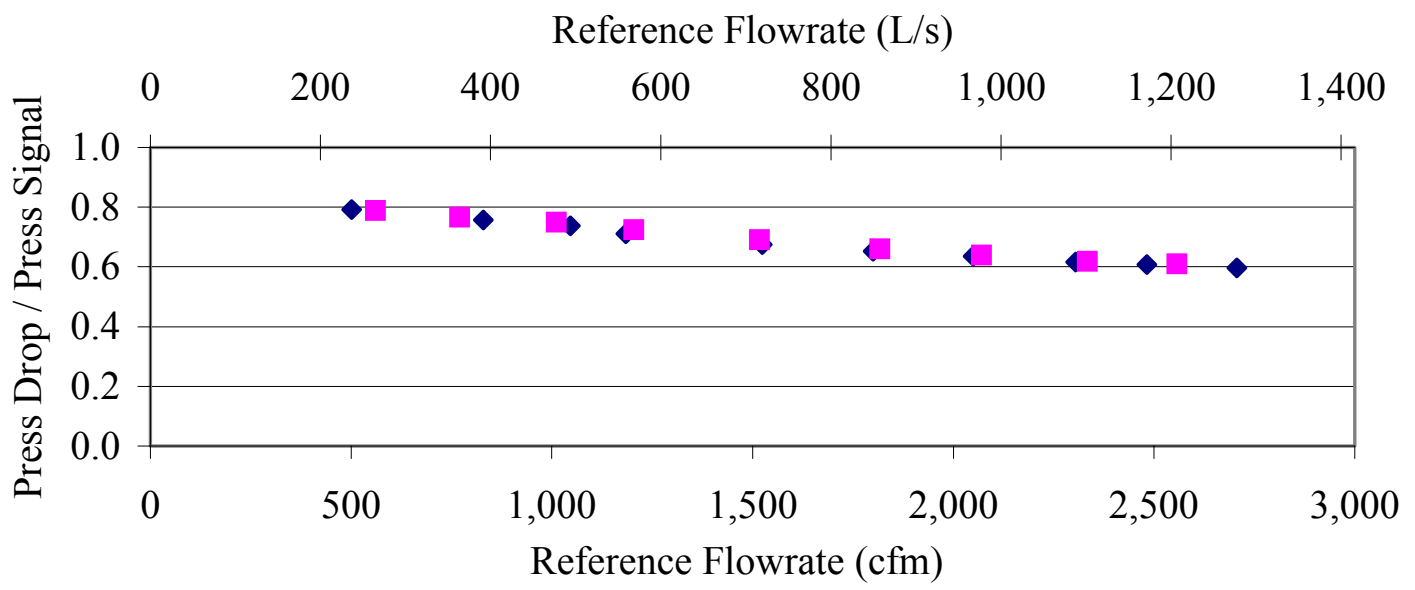

Figure 18. Pressure drop ${ }^{20}$ of MT5 with no upstream OA louver as a fraction of the pressure signal that indicates OA flow rate.

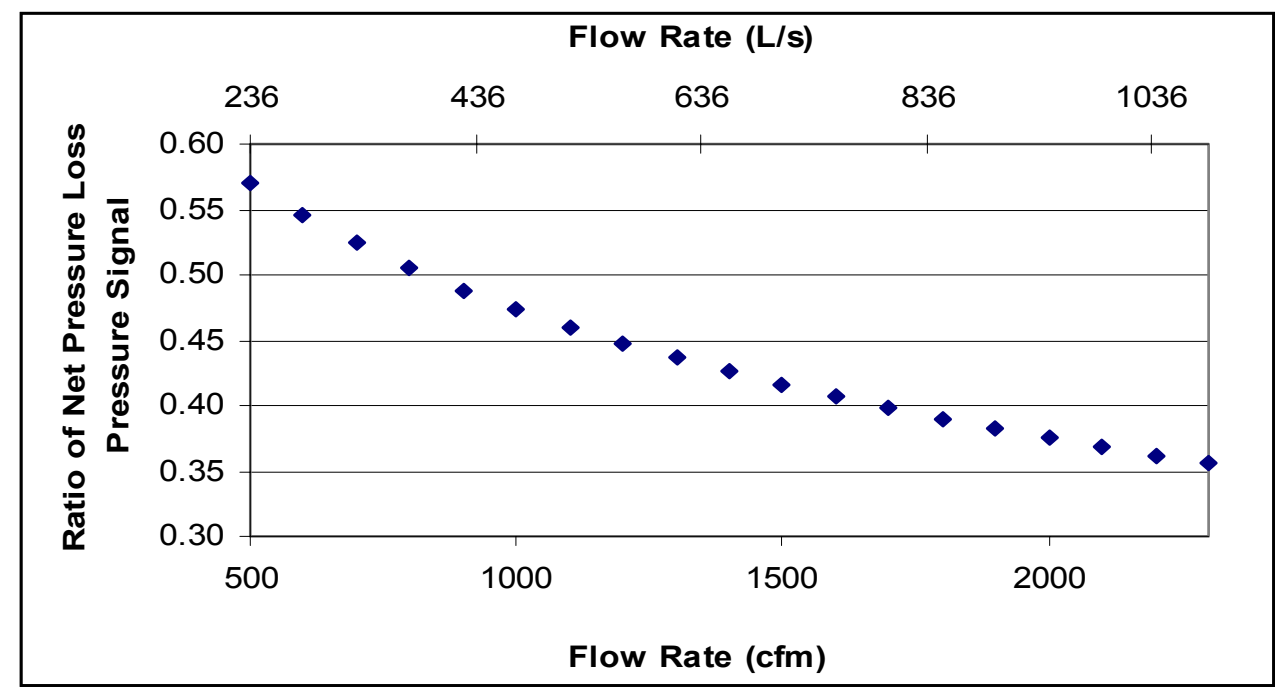

Figure 19. Net pressure drop of MT5 as a fraction of the pressure signal used to determine outdoor air flow rate, versus outdoor air flow rate.

modified louver used at the inlet of MT5. Therefore, it is likely that the curve in Figure 19 slightly underestimates the net pressure drop of MT5.

${ }^{20}$ The different data point markers represent data from different series of tests that used different dampers to control air flow rate. 


\section{Comparison of Technologies}

Table 4 compares the performance of all measurement technologies. MT1, and MT3 - MT5 should be usable at the maximum recommended rates of OA flow through louvers, although the errors with MT3, used with data from the louver manufacturer, were as high as $28 \%$ even with a research grade pressure transducer employed to measure the pressure signal that indicates OA flow. MT5 clearly has the largest pressure signal, which is a desirable feature given the uncertain accuracy and infrequent calibrations of pressure transducers used in many buildings. All of the measurement devices have pressure drops that are likely to be judged acceptable. MT5 has the largest pressure drop of 0.17 IWG (43 Pa) at the maximum OA flow rate. Several technologies impose a negligible pressure drop.

If a building has an economizer control system, during periods of minimum OA supply to the building, the flow rates of OA through the measurement technology may be reduced to $20 \%$ of the maximum recommended rate of flow through the upstream louver. Under these conditions, the pressure signals of MT1, MT3, and MT4 are very small and very difficult to measure accurately. With $20 \%$ of the maximum recommended flow rate, errors of only \pm 0.01 IWG $( \pm 2 \mathrm{~Pa})$ in measuring pressure differences will lead to errors in measurement of OA flow rates that sometimes exceed $100 \%$. For MT3, we estimated the air flow rates needed to limit errors to $20 \%$ from an uncertainty in measuring pressure difference of \pm 0.01 IWG $( \pm 2 \mathrm{~Pa})$. The required air flow rates are $27 \%, 42 \%$ and $37 \%$ of the recommended maximum flow rates for use of MT3 with L1, L2, and L3, respectively. In contrast, MT5 has a larger pressure signal, consequently the errors in measuring minimum OA flow rates through L1 with MT5 should be $20 \%$ or less. However, MT5 is a prototype that is not available commercially.

MT1, MT3, and MT4 could be used in buildings with economizer control systems; however, to maintain accurate measurements of OA flow rate it will be necessary to divide the OA intake into two sections, each with a separate OA damper system. The economizer control system and associated controls must be designed and programmed to maintain rates of $\mathrm{OA}$ flow through the measurement technologies that are sufficient to produce a accurately measured pressure signals when rates of OA supply are minimized.

Our data indicate that MT2 used with horizontal probes in conjunction with L1 was accurate within $20 \%$ to $30 \%$ depending on the probe location and that higher accuracy could be obtained if an accurate fieldbased calibration is available. The accuracy with other types of upstream lovers may be different. 
Table 4. Comparison of performance of measurement technologies.

\begin{tabular}{|c|c|c|c|c|c|c|c|c|}
\hline \multirow[b]{2}{*}{$\begin{array}{l}\text { Meas. } \\
\text { Tech- } \\
\text { nology }\end{array}$} & \multirow[b]{2}{*}{ Louver } & \multicolumn{4}{|c|}{ Max. Flow Through Louver } & \multicolumn{3}{|c|}{$\begin{array}{l}20 \% \text { of Max Flow Through } \\
\text { Louver* }\end{array}$} \\
\hline & & $\begin{array}{l}\text { Flow } \\
\text { Rate } \\
\text { CFM } \\
(\mathrm{L} / \mathrm{s})\end{array}$ & $\begin{array}{c}\text { Press. } \\
\text { Signal } \\
\text { IWG } \\
(\mathrm{Pa})\end{array}$ & $\begin{array}{c}\text { Press. } \\
\text { Drop } \\
\text { IWG } \\
(\mathrm{Pa})\end{array}$ & $\begin{array}{l}\text { Calibra- } \\
\text { tion } \\
\text { Error } \\
\text { (Bias) }\end{array}$ & $\begin{array}{l}\text { Flow } \\
\text { Rate } \\
\text { CFM } \\
(\mathrm{L} / \mathrm{s})\end{array}$ & $\begin{array}{c}\text { Press. } \\
\text { Signal } \\
\text { IWG } \\
(\mathrm{Pa})\end{array}$ & $\begin{array}{l} \pm 0.01 \\
\text { IWG } \\
( \pm 2 \mathrm{~Pa}) \\
\text { Error }^{\#}\end{array}$ \\
\hline 1 & 1 & $\begin{array}{c}2300 \\
(1090)\end{array}$ & $\begin{array}{l}0.23 \\
(57)\end{array}$ & $\begin{array}{l}\sim 0 \\
(\sim 0)\end{array}$ & $<5 \%$ & $\begin{array}{l}460 \\
(220) \\
\end{array}$ & $\begin{array}{l}0.007 \\
(1.9)\end{array}$ & $\begin{array}{c}-100 \% \text { to } \\
+54 \%\end{array}$ \\
\hline 2 & 2 & $\begin{array}{c}615 \\
(290)\end{array}$ & $\begin{array}{c}\text { NA } \\
\text { (NA) }\end{array}$ & $\begin{array}{l}\sim 0 \\
(\sim 0)\end{array}$ & $\begin{array}{c}-23 \% \text { to } \\
-32 \% \wedge \\
+114 \% * *\end{array}$ & $\begin{array}{l}120 \\
(58)\end{array}$ & $\begin{array}{c}\text { NA } \\
\text { (NA) }\end{array}$ & $\begin{array}{c}\text { NA } \\
\text { (NA) }\end{array}$ \\
\hline 3 & 1 & $\begin{array}{c}2300 \\
(1090)\end{array}$ & $\begin{array}{c}0.224 \\
(56)\end{array}$ & $\begin{array}{l}0 \\
(\sim 0)\end{array}$ & $+24 \%$ & $\begin{array}{l}460 \\
(220) \\
\end{array}$ & $\begin{array}{c}\sim 0.01 \\
(\sim 2)\end{array}$ & $\begin{array}{l}\sim-70 \% \text { to } \\
\sim+40 \%\end{array}$ \\
\hline 3 & 2 & $\begin{array}{c}615 \\
(290) \\
\end{array}$ & $\begin{array}{c}0.108 \\
(27)\end{array}$ & $\begin{array}{l}\sim 0 \\
(\sim 0)\end{array}$ & $+28 \%$ & $\begin{array}{l}120 \\
(58)\end{array}$ & $\begin{array}{l}\sim 0.001 \\
(\sim 0.2)\end{array}$ & $\begin{array}{l}-100 \% \text { to } \\
+200 \%\end{array}$ \\
\hline 3 & 3 & $\begin{array}{l}1220 \\
(580)\end{array}$ & $\begin{array}{c}0.148 \\
(37)\end{array}$ & $\begin{array}{l}\sim 0 \\
(\sim 0)\end{array}$ & $+20 \%$ & $\begin{array}{c}240 \\
(110)\end{array}$ & $\begin{array}{l}<0.01 \\
(<2.5)\end{array}$ & $\begin{array}{l}-100 \% \text { to } \\
>100 \%\end{array}$ \\
\hline 4 & 1 & $\begin{array}{c}2300 \\
(1090)\end{array}$ & $\begin{array}{c}0.053 \\
(13)\end{array}$ & $\begin{array}{c}0.092 \\
(23)\end{array}$ & $<10 \%$ & $\begin{array}{l}460 \\
(220)\end{array}$ & $\begin{array}{l}\sim 0.002 \\
(\sim 0.5)\end{array}$ & $\begin{array}{l}-100 \% \text { to } \\
+120 \%\end{array}$ \\
\hline 5 & 1 & $\begin{array}{c}2300 \\
(1090)\end{array}$ & $\begin{array}{c}0.48 \\
(120)\end{array}$ & $\begin{array}{l}0.17 \\
(43)\end{array}$ & $\begin{array}{c}\text { Not } \\
\text { available }\end{array}$ & $\begin{array}{c}460 \\
(220)\end{array}$ & $\begin{array}{c}0.024 \\
(6)\end{array}$ & $\begin{array}{l}-20 \% \text { to } \\
+17 \%\end{array}$ \\
\hline
\end{tabular}

*Expected minimum OA flow rate if HVAC system has an economizer control system

\#Estimated errors resulting solely from a $\pm 0.01 \mathrm{IWG}( \pm 2 \mathrm{~Pa})$ error in pressure signal measurement.

$\wedge$ With horizontal probes. $* *$ With vertical probes

\section{Discussion}

Testing methods

The test system and protocol developed for this project provided a convenient and accurate method of evaluating the accuracy of the measurement technologies under conditions without wind. Individual data points could be obtained rapidly (e.g., within one minute) after flow rates were adjusted to obtain the desired conditions. If large numbers of tests were required, a computer control system could be developed to automatically adjust damper positions and fan speeds. Replacing the large reference flow meter with the smaller reference flow meter (or vice versa) required approximately 15 minutes of labor. Removing and replacing the OA flow measurement technology in the experimental system may require up to several hours of labor, depending upon the technology. The main limitation of the test apparatus and protocol is that they do not evaluate the influence of winds on measurement system accuracy. Preliminary testing with simulated winds indicates that winds can reduce accuracy, presumably by causing uneven airflow through the OA intake louvers. To confirm the reliability of data obtained with simulated winds we believe that limited testing should be performed with the systems exposed to real winds.

\section{Performance of Measurement Technologies}

We have not surveyed potential users of OA measurement technologies to assess their accuracy requirements. However, considering the complete lack of an OA air flow rate measurement technology in 
most buildings and the imprecise knowledge of the relationship of OA ventilation rates with health, we anticipate that systems with an accuracy on the order of $\pm 20 \%$ will be considered valuable by users.

The series of tests identified three commercially available measurement technologies, MT1, MT3, and MT4 that should provide reasonably accurate measurements of OA flow rates as long as air velocities are maintained high enough to produce accurately measurable pressure signals ${ }^{21}$. In practice, this can be accomplished by dividing the OA intake into two sections, each with a separate OA damper system. The economizer control system and associated controls must be designed and programmed to maintain rates of OA flow through the measurement technologies that are sufficient to produce a accurately measured pressure signals when rates of OA supply are minimized.

Because MT2 uses electronic velocity sensors, it maintains an accurately measurable output signal at lower air velocities than pressure-based velocity sensors. With probes installed horizontally, MT2 was accurate within approximately $20 \%$ to $30 \%$ when we multiplied the indicated air velocity by the cross sectional area of the duct section downstream of the louver. Regardless of the probe configuration or probe location, the output signal of MT2 varied approximately linearly with reference OA flow rate, indicating that good accuracy could be obtained with MT2 if an accurate field-based calibration was possible. We believe that accurate calibrations in field settings, i.e., accurate measurements of rates of OA flow into HVAC systems, will often be very difficult to obtain, but this is an opinion not verified in this research.

In our tests of MT2 with probes installed vertically, the errors in OA flow measurements made with MT2 were greater than $100 \%$. We performed additional tests in an attempt to determine the cause of the errors. When the probes of MT2 were located in a duct section between upstream and downstream air flow straighteners, the same air velocity within a few percent was indicated with horizontal and vertical probes. Therefore, there was no bias inherent from probe orientation. When the probes were installed horizontally and vertically 15.5 inch $(39 \mathrm{~cm})$ downstream of downstream edge of L2 and 20 inch $(51 \mathrm{~cm})$ upstream of a flow straightener, the velocity indicated with horizontal and vertical probes differed by approximately $30 \%$. When horizontal and vertical probes were installed 15.5 inch $(39 \mathrm{~cm})$ downstream of downstream edge of the L2 and 7.5 inch $(19 \mathrm{~cm})$ upstream of upstream edge of the damper, which replicates the initial test conditions, we again obtained a much higher air velocity reading, by more than $100 \%$, with the probes oriented vertically. These exploratory tests suggest that the louver and damper produce highly non-uniform air velocities in the plane of the probes that can cause large measurement errors. When we used a hot wire anemometer to investigate the velocity profile downstream of L2 in the plane of the MT2's probes we found that velocities were highly non-uniform. Downstream of L3 (not L2), we also used chemical smoke to informally study airflow patterns and found evidence of large turbulent eddies. We suspect that similar eddies may develop downstream of L2. Thus, the large errors found in out tests with vertical probes may be particular to the type of upstream louver, downstream damper, and the probe installation locations of our tests. The non-uniform airflow profiles downstream of louvers make it difficult to accurately measure OA flow rates without some type of flow straightening. Unfortunately, we did not have the resources necessary to evaluate the accuracy of MT2 located downstream of the other louvers. The more uniform air velocity profile downstream of L1 might result in more accurate measurements of OA flow rates with MT2.

MT3, in combination with manufacturer's data on pressure drops across louvers, was tested with three different louver systems. When flow rates were maintained sufficiently high for accurate pressure difference measurements, the measurement errors were $\pm 20 \%$ to \pm 30 percent. If an accurate calibration was performed in the field, errors could be further reduced; however, inaccurate field based calibrations might lead to larger errors. While these results are encouraging, we cannot be confident that a similar

${ }^{21}$ The accuracy of MT4 may depend on the type of upstream louver. 
level of measurement accuracy will occur with other types or sizes of louvers. Our confidence in this measurement method would be improved if MT3 were supplied integrated with a louver and damper system, with a factory calibration.

The performance of MT4 may also depend on the type of louver used upstream. We placed MT4 downstream of L1. The configuration of L1 causes air to enter the airflow straightener with a fairly uniform velocity, which, in turn, should improve the accuracy of MT4. In contrast, L2 would direct air preferentially toward the bottom of the airflow straightener and L3 would direct air toward the top of the airflow straightener. Thus, it is possible that MT4 would be considerably less accurate if placed downstream of L1 or L3.

The prototype measurement technology MT5 is the only one that appears suitable for measuring OA flow rates over the full range from $20 \%$ OA to $100 \%$ OA. However, the prototype is not a commercially available product and more work on the technology design and fabrication plus additional testing would be necessary before a practical version of MT5 could be produced.

To better assess the accuracy of these OA measurement devices in practice, we need improved information on the accuracy of pressure difference measurements made in real building HVAC systems. To produce Table 3, we have assumed, based on our experience, that $\pm 0.01 \mathrm{IWG}( \pm 2 \mathrm{~Pa})$ is a typical level of uncertainty. However, the manufacturer's accuracy specifications for some pressure transducers marketed for use in HVAC systems imply better accuracy. For example, one manufacturer's specifications imply that uncertainties are as low as \pm 0.001 IWG $( \pm 0.25 \mathrm{~Pa})$ for a pressure transducer with a full scale range of 0.1 IWG $(25 \mathrm{~Pa})$ and as low as $0.0025 \mathrm{IWG}(0.6 \mathrm{~Pa})$ for a transducer with a full scale range of 0.25 IWG (62 Pa). Calibrations to confirm such a high level of accuracy are very difficult. If pressure transducers are indeed as accurate in actual use as indicated by manufacturers, MT1 and MT3 may be useable for measuring the minimum rate of OA supply in HVAC systems with economizer controls, without providing a separate OA damper system for minimum OA.

None of the measurement technologies have large pressure drops that are likely to be judged unacceptable. Thus, pressure drop limitations do not appear to be a barrier to measurement of OA flow rates into HVAC systems.

Most of the measurement systems do require that the OA damper is located a significant distance downstream of the OA louver. The recommended or required distance between the downstream edge of louver and upstream edge of the fully open OA damper is approximately 4, 14, and 15 inch $(10,36$, and $38 \mathrm{~cm}$ ) for MT1, MT2, and MT4 respectively. No guidance was identified for MT3. The prototype of MT5 required 18 inch $(46 \mathrm{~cm})$ between the louver and OA damper, although this length might be reduced substantially through changes in design.

Costs are another consideration and we don't know what level of costs will be deemed acceptable. We paid $\$ 800$ for MT1, $\$ 200$ for MT2, $\$ 450$ for MT3 ${ }^{22}$, and $\$ 1100$ for MT4, all without any associated pressure sensors or controls. MT1 included an integral louver and MT4 included an integral OA damper, so the net costs of the measurement technologies are less than indicated above. HVAC equipment manufacturers who purchase large numbers of products might be able to obtain systems a lower cost. Given the potential energy cost savings and health benefits of providing better control of OA supply rates, we suspect that these product costs will be acceptable.

\footnotetext{
${ }^{22}$ With a single downstream pressure probe which is called an inlet airflow sensor by the manufacturer. If multiple probes are used the cost per probe is $\$ 75$.
} 
This research effort did not evaluate all commercially available technologies for measuring rates of OA flow into HVAC systems. We are aware of two additional technologies that utilize pressure-taps placed on or between the blades of the OA damper. Because high air velocities are maintained between damper blades even when OA flow rates diminish, these measurement devices may maintain accurately measurable pressure signals even when $\mathrm{OA}$ flow rates are at a minimum.

\section{Conclusions}

The test system and protocol developed for this project provides a convenient and accurate method of evaluating the accuracy of technologies for measuring outdoor airflows into air handling systems. Further research is needed to develop systems and protocols for assessing the influence of winds on measurement accuracy.

The series of tests performed for this research identified three commercially available measurement technologies that should provide reasonably accurate measurements of OA flow rates (i.e., 10\% to $30 \%$ errors) as long as air velocities are maintained high enough to produce accurately measurable pressure signals. In practice, these conditions can be achieved by dividing the OA intake into two sections, each with a separate OA damper system. The economizer control system and associated controls must be designed and programmed to maintain rates of OA flow through the measurement technologies that are sufficient to produce a accurately measured pressure signals when rates of OA supply are minimized. A fourth commercially-available measurement technology with electronic velocity sensors was accurate within approximately $20 \%$ to $30 \%$ when the probes were installed horizontally, but errors were much larger with vertical probes.

A prototype of a new technology for measuring rates of OA flow was designed and constructed. The prototype measurement technology was the only one that has a sufficiently large pressure signal for measurement of OA flow rates over their full range from $20 \%$ OA to $100 \%$ OA. However, the prototype is not a commercially available product.

All of the measurement devices have pressure drops that are likely to be judged acceptable. Thus, pressure drop limitations do not appear to be a barrier to measurement of OA flow rates into HVAC systems.

\section{Acknowledgements}

This work was supported by the assistant Secretary for Energy Efficiency and Renewable Energy, Building Technologies Program of the U.S. Department of Energy under contract DE-AC03-76SF00098. The authors thank Woody Delp and Steve Taylor for their reviews of a draft of this document.

\section{References}

ASHRAE (1999) ANSI/ASHRAE Standard 62-1999 - Ventilation for acceptable indoor air quality. American Society of Heating, Refrigerating, and Air Conditioning Engineers, Inc. Atlanta, GA ASHRAE (2001) ANSI/ASHRAE Standard 62-2001 - Ventilation for acceptable indoor air quality. American Society of Heating, Refrigerating, and Air Conditioning Engineers, Inc. Atlanta, GA ASHRAE (1999a) ANSI/ASHRAE Standard 120-1999 (1999) Method of testing to determine flow resistance of hvac ducts and fittings. ASHRAE, Atlanta, GA

ASHRAE (1999b)ANSI/ASHRAE 51-1999 (1999) Laboratory methods of testing fans for aerodynamic performance rating. ASHRAE, Atlanta, GA 
Emmerich SJ and Persily AK (1998) Energy impacts of infiltration and ventilation in U.S. office buildings using miultizone airflow simultion. Proceedings of IAQ and Energy 98, pp. 191-206, ASHRAE, Atlanta, GA.

Fisk WJ, Faulkner D, Sullivan D, Delp W (2003) Outdoor airflow into HVAC systems: an evaluation of measurement technologies. LBNL-53834, Lawrence Berkeley National Laboratory Report, Berkeley, CA

Howell, RH and Sauer HJ (1987) Velocity variation effects on a rotating vane anemometer at coil faces. ASHRAE Transactions 93(2): 200-210

Kettler JP (1995) Minimum ventilation control for VAV systems: fan tracking versus workable solutions. ASHRAE Transactions 101(2): 625-630

Krarti, M, Brandemuehi MJ, Schroeder C, Jeannette E (1999) Techniques for measuring and controlling outside air intake rates in variable air volume systems. Final Report of ASHRAE Research Project RP-980, ASHRAE, Atlanta.

Lagus Applied Technologies (1995) Air change rates in non-residential buildings in California, Report P400-91-034BCN, California Energy Commission, Sacramento, CA.

Orme, M. (1998) Energy impact of ventilation, Technical Note 49, International Energy Agency - Air Infiltration and Ventilation Centre, Coventry, Great Britain.

Persily A (1989) Ventilation rates in office buildings. Proceedings of the IAQ'89 Conference The Human Equation: Health and Comfort, pp. 128-136., ASHRAE, Atlanta.

Persily A and Gorfain J (2004) Analysis of office building ventilation data from the U.S., Environmental Protection Agency Building Assessment Survey and Evaluation (BASE) study. NISTIR-7145, National Institute of Standards and Technology, U.S. Department of Commerce.

Schroeder CC, Krarti M, Brandemuehl MJ (2000) error analysis of measurement and control techniques of outside air intake rates in VAV systems. ASHRAE Transactions 106(2): pp26

Seppanen, O.A., Fisk, W.J., and Mendell, M.J. (1999) Association of ventilation rates and $\mathrm{CO}_{2}$ concentrations with health and other human responses in commercial and institutional buildings. Indoor Air 9: 226-252.

Turk, B.H., Brown J.T., Geisling-Sobatka, K., Froelich, D.A., Grimsrud, D.T., Harrison, J., Koonce, J.F., Prill, R.J., and Revzan, K.L. (1987) Indoor Air Quality and Ventilation Measurements in 38 Pacific Northwest Commercial Buildings--Volume 1: Measurement Results and Interpretation, Lawrence Berkeley Laboratory Report, LBL-22315 1/2, Berkeley, CA.

Womble SE, Ronca EL, Girman JR, Brightman HS (1996) Developing Baseline Information on Buildings and Indoor Air Quality (BASE'95). Proceedings of ASHRAE IAQ'96, Paths to Better Building Environments, pp 109-117, ASHRAE, Atlanta. 